\title{
Requirements for using information and communication technology in agricultural extension work in Assiut governorate, Egypt
}

\author{
Murad E. H. E. T., Khalifa I. A. A., Abdelsalam M. F. S. , Salem H. E. A. \\ Department of Agricultural Extension and Rural Sociology, Faculty of Agriculture, Al-Azhar University, Assuit, Egypt
}

\begin{abstract}
This research aimed to identify the requirements of using information and communication technology in agricultural extension work in Asyut Governorate, and the degree of the impact of these requirements on agricultural extension work in the research area. This research was conducted on the majority all the employees of the agricultural extension agency in the governorate of Assiut, whose number at the time of conducting the research was 135 extension workers, Data were collected through personal interviews by a questionnaire was A prepared to that specially, Frequencies, Percentages, the mean, were used for data presentation and analysis SPSS program. The results could summarize as follows:

- The results showed that the majority of the respondents $(85,0 \%$ of them) are aged 50 years or over, and the majority (74,1\% of them) are of rural origin, although $74,8 \%$ of them don't possess agricultural holdings, and $69,6 \%$ of them have a diploma in agriculture, and the majority of them $(85.1 \%)$ were working in agricultural field for 20 years or more, while $45.2 \%$ of them have been working in agricultural extension for 20 years or more, Most of them (77.0\% of them) didn't receive training courses in the field of information and communication technology, so the majority of them $(91.1 \%$ of them) had low benefit from training in this field, and $40.7 \%$ of them don't own computers (at home or work), and the majority of respondents ( $99.3 \%$ of them) have a mobile phone, and $48.1 \%$ of them have internet (wired, or wireless "WiFi") at home, while $47.7 \%$ of them don't have internet (wired, or wireless "Wi-Fi").

- 2-. The majority of respondents agreed to the proposed items as requirements for the use of information and communication technology in agricultural extension work, which numbered 24 items with rates ranging between ( $94.8 \%$ $-89.6 \%$ ) to develop the infrastructure requirements necessary for the use of information and communication technology in agricultural extension work, $(97.0 \%-92.6 \%)$ the requirements for training and qualification of the agricultural extension work environment (workers in the agricultural extension apparatus, and farmers) to suit the use of information and communication technology in agricultural extension work, and (96.3\% - 91.1\%) To develop a national strategy for the use of information and communication technology in extension work agricultural.

- The most important requirements for the use of information and communication technology in agricultural extension work were the importance and impact of agricultural extension work from the viewpoint of the respondents, arranged as follows: requirements for the development of a national strategy for the use of information and communication technology in agricultural extension work with an average from $75 \%$ to $55 \%$, followed by requirements for training and rehabilitation of the environment agricultural extension work (workers, farmers) to fit the use of information and communication technology in agricultural extension work with an average from $69 \%$ to $35 \%$, and ranked last in the requirements for developing the infrastructure needed to use information and communication technology in agricultural extension work, with an average from $67 \%$ to $20 \%$.
\end{abstract}

Keywords: information and communication technology, agricultural extension work, Assiut governorate.

* Corresponding author: Abdelsalam M. F. S., 


\title{
متطلبات استخدام تكنولوجيا المعلومات و الاتصال في العمل الإرشادي الزر اعي بمحافظة أسيوط بجمهورية مصر العربية
}

\author{
السيد حسين السيد طلعت مر اد ، إبر اهيم عبدالرحمن علي خليفة ، محمد فوزي سالمان عبد السلام ، حازم العريان عبد اللطيف سالم \\ قسم الإرشاد الزر اعي و المجتمع الريفي ، كلية الزراعة ، جامعة الأزهر - فرع أسيوط ، جمهورية مصر العربية
}

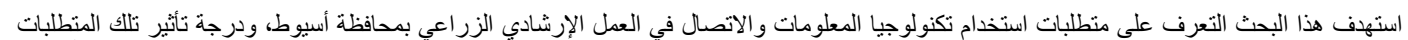

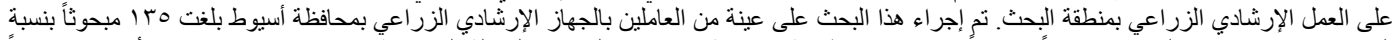

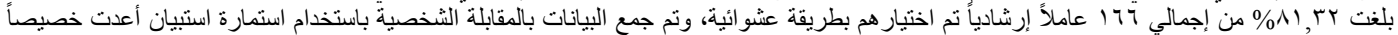

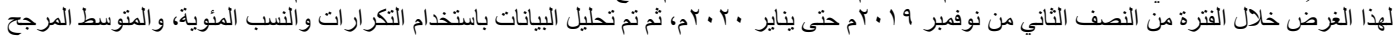

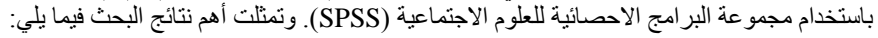

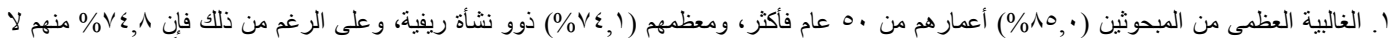

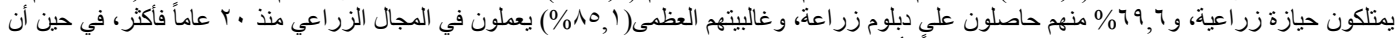

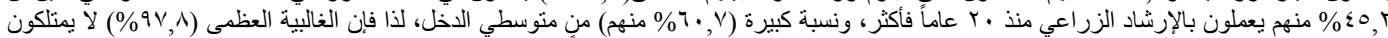

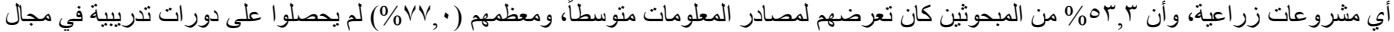

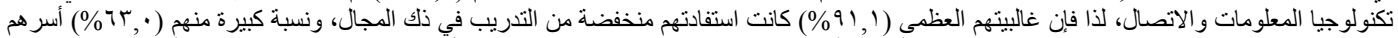

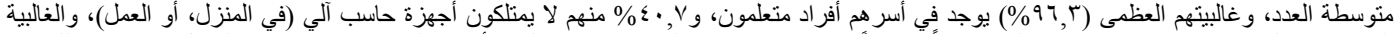

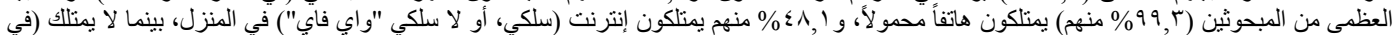

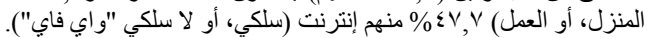

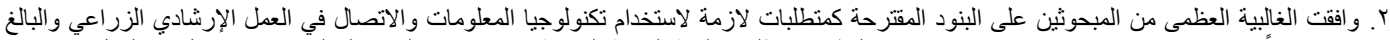

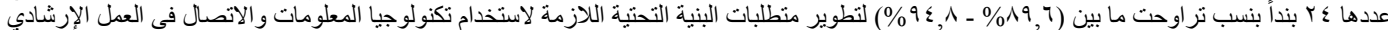

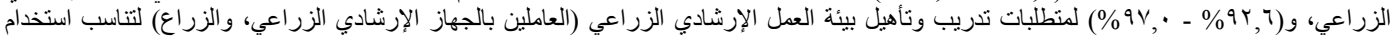

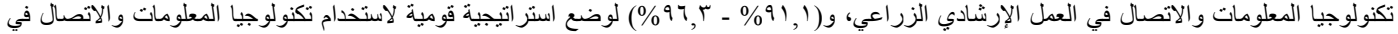
العمل الإرشادي الزراعي.

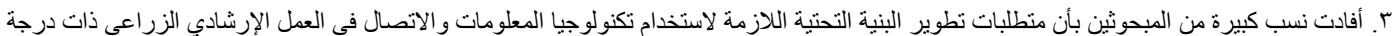

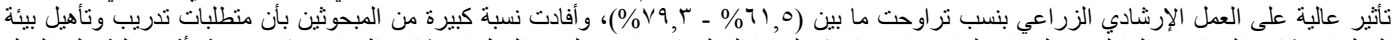

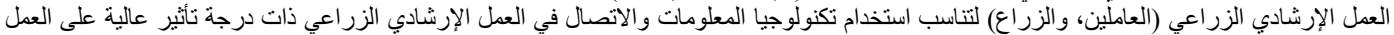

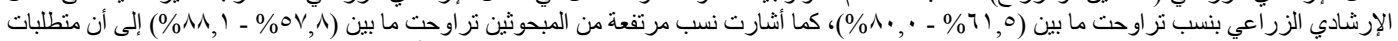

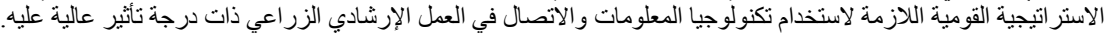

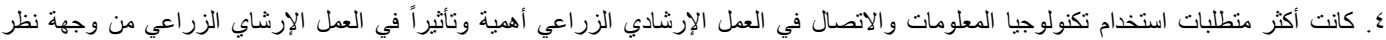

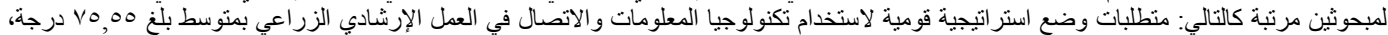

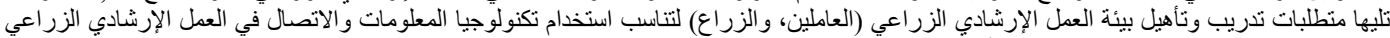

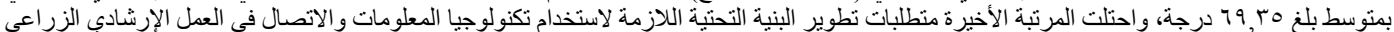

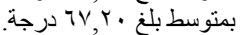

كلمات دالة: تكنولوجيا المعلومات والاتصال، العمل الإرشادي الزر اعي، محافظة أسيوط. 
الأفكار الزراعية المستحدثة لكافة المناطق الريفية، وتوصيل

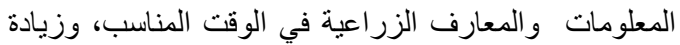

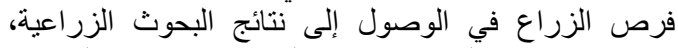

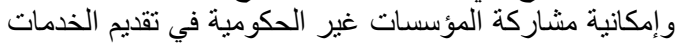

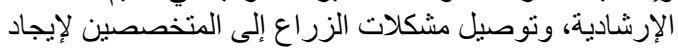

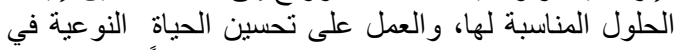

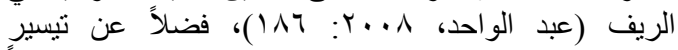

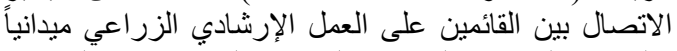

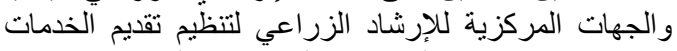

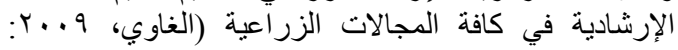

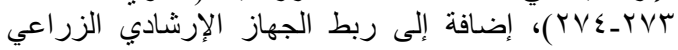

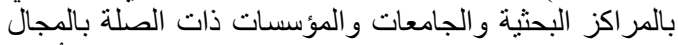

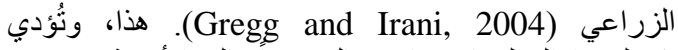

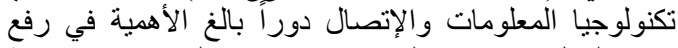

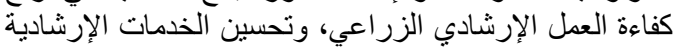

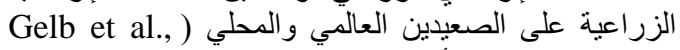

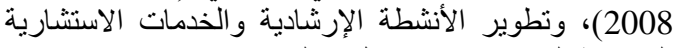

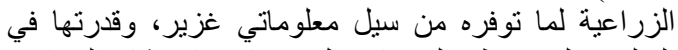

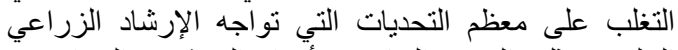

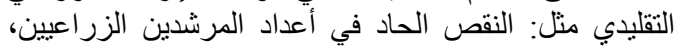

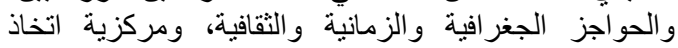
القرار بما توفره من فرص وخدمات ولجنات اتصالية عالية الكفاءة

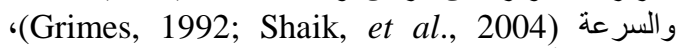

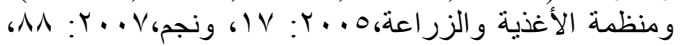

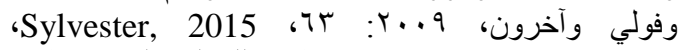

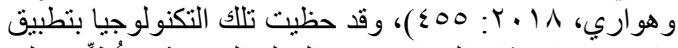

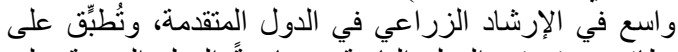

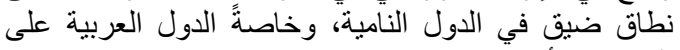

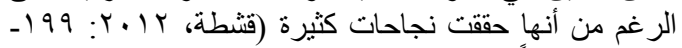

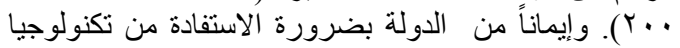

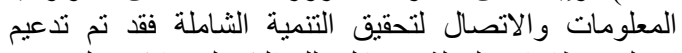

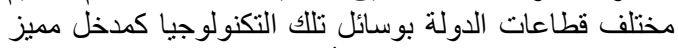

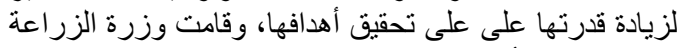

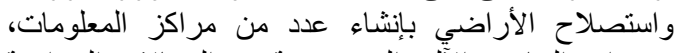

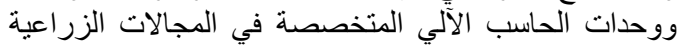

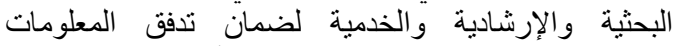

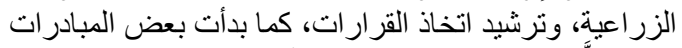

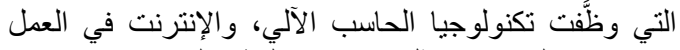

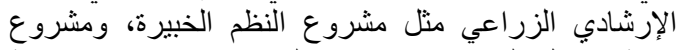

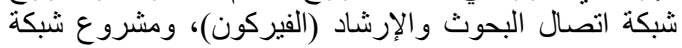

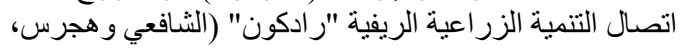

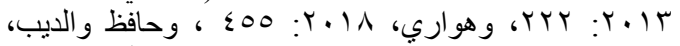

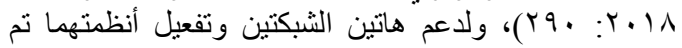

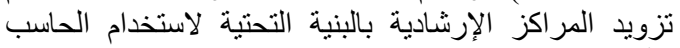

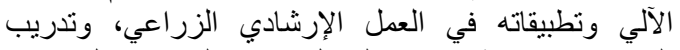

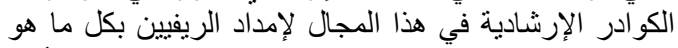

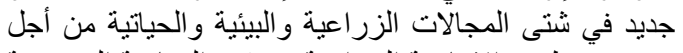
تحسين وتطوير الإنتاجية الزراعية والزراعة وليثية الرفاهية المجتمعية المنية
مقدمة

يعتبر الجهاز الإرشادي الزراعي أحد الأجهزة الهامة المعنية

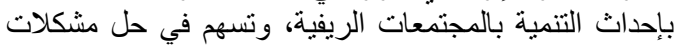

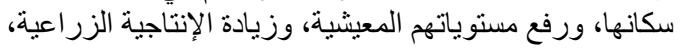

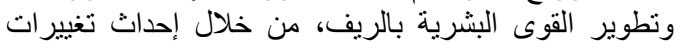

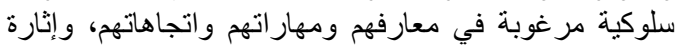

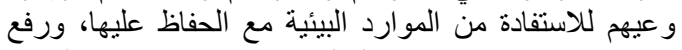

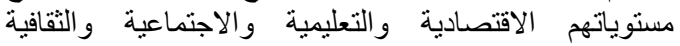

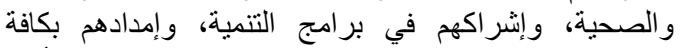

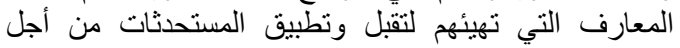

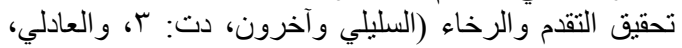

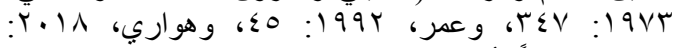

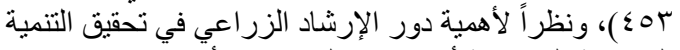

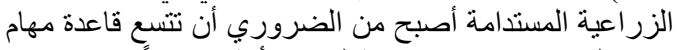

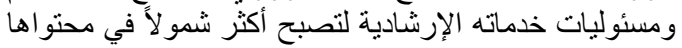

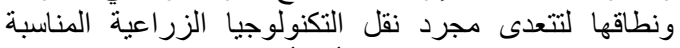

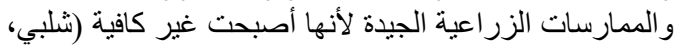

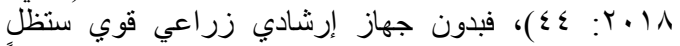

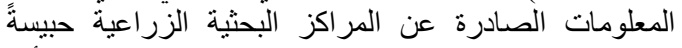

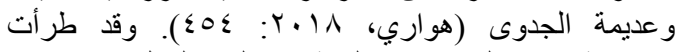

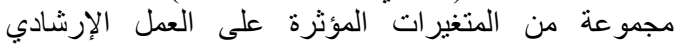

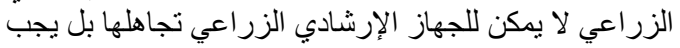

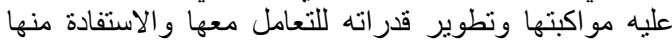

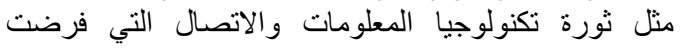

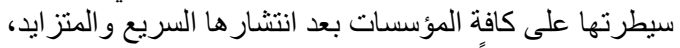

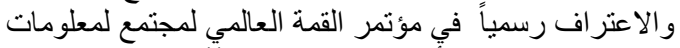

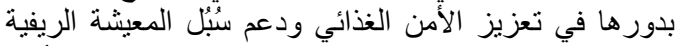

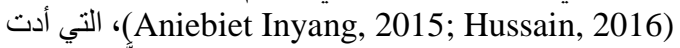
إلى مضاعفة حجم المعلومات المتداولة والمخزنة لقدرنها

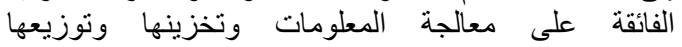

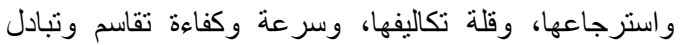

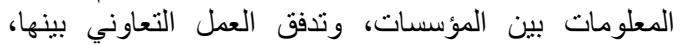

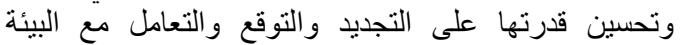

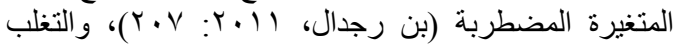

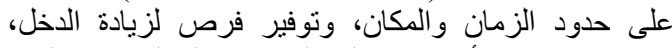
وتزيد من قدرة الأشخاص ولاص على المشاركة الفعالة في عمليات

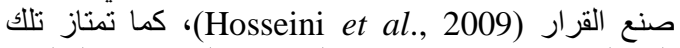

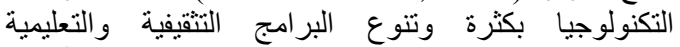

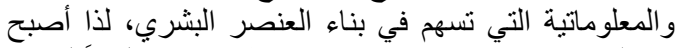

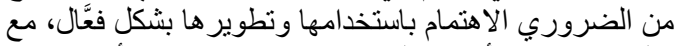

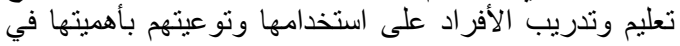

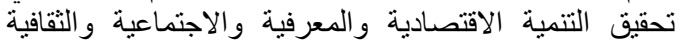

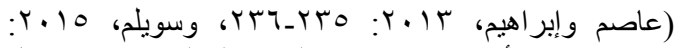

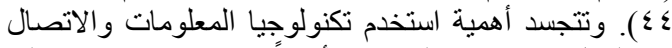

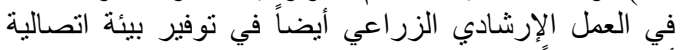

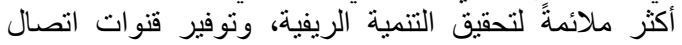
واسعة ومتتوعة لخدمة القطاع الإرشادي الزئة الزراعي، ونشر الترال 
الزراعي بمحافظة أسيوط ليصل إلى هب إعاملاً إرشادياً عام

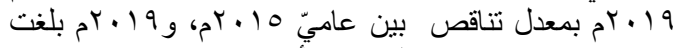

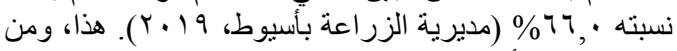

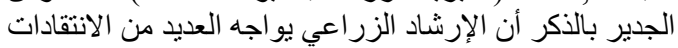

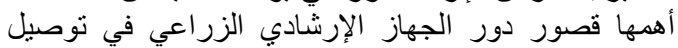

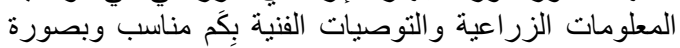

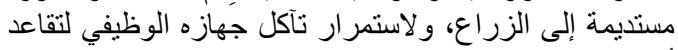

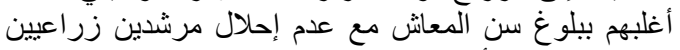

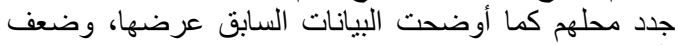

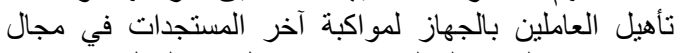

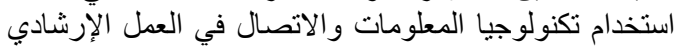

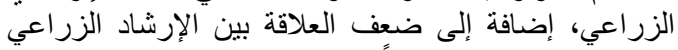

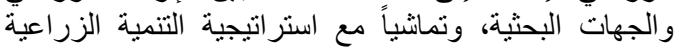

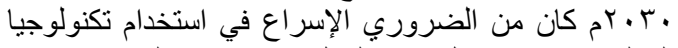

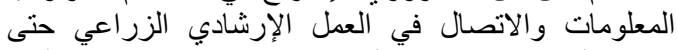

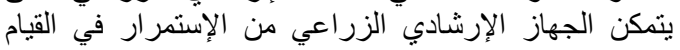

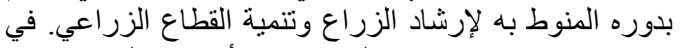

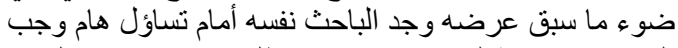

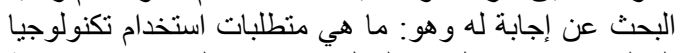

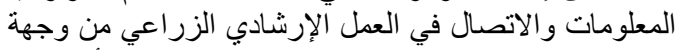

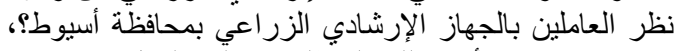

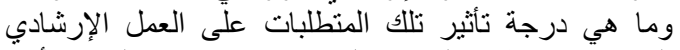

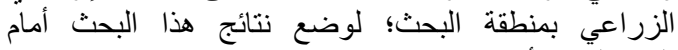

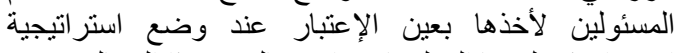
استخدام تكنولوجيا المعلومات و الاتصنال في هذا المجال.

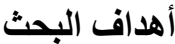

يهدف هذا البحث إلى تحقيق الأهداف التالية:

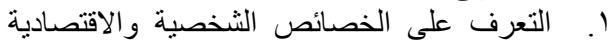

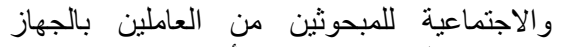
الإرشادي الزر اعي بمحافظة أسيوط.

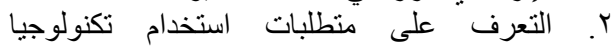
المعلومات و والاتصال في في العمل الغئل الإرشادي الزراعي من وجهة نظر المبحوثين. r. تحديد درجة تأثثر منطلبات استخدام تكنولوجيا

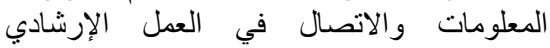
الزر اعي على العمل الإرشادي الزر اعي من وجهة الإنية

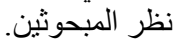

\section{طريقة إجراء البحث}

تم إجراء هذا البحث على عينة عشوائية من العاملين بالجهاز

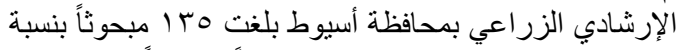

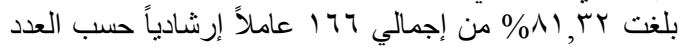

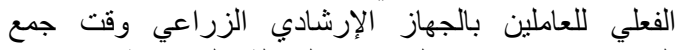

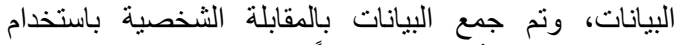

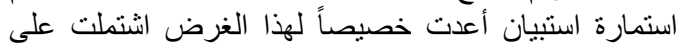

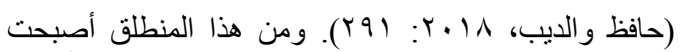
قدرة وكفاءة العاملين بالإرشاد الزبار الزاعي على هلى استخدام أجهزة

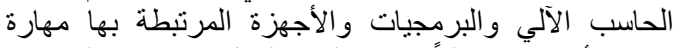

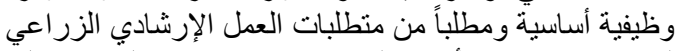

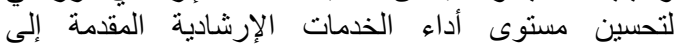

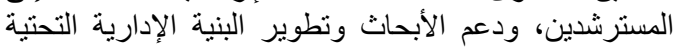

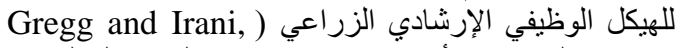

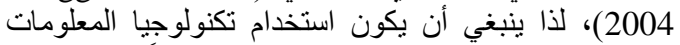

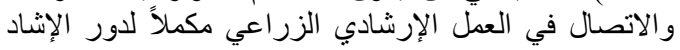

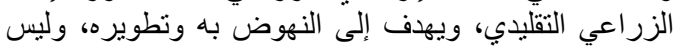

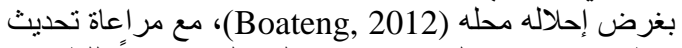

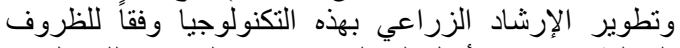

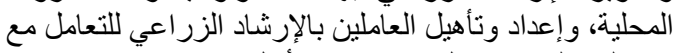

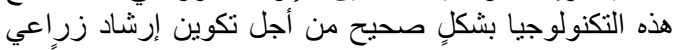

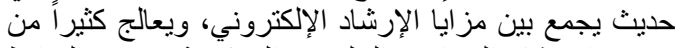

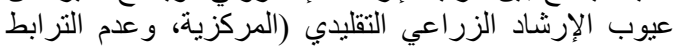

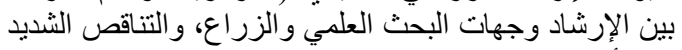

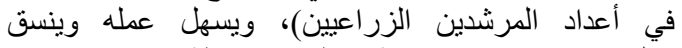

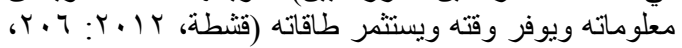

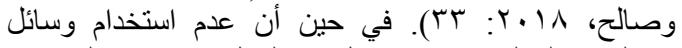

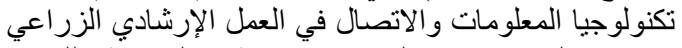

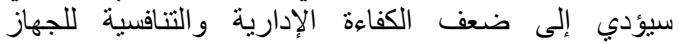

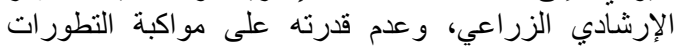

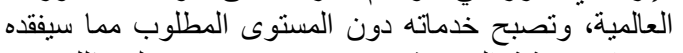

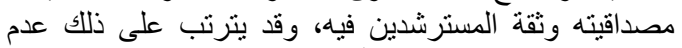

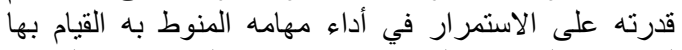

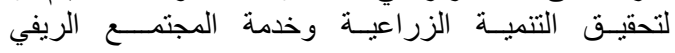
.(Agha et al., 2018)

\section{مشكلة البحث}

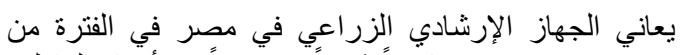

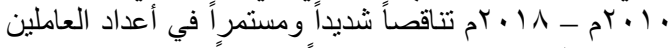

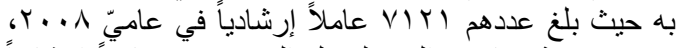

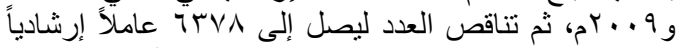

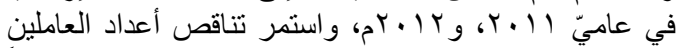

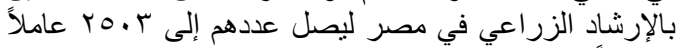

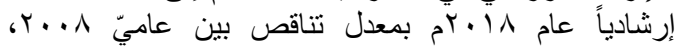

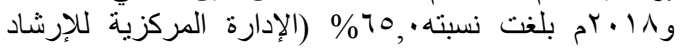

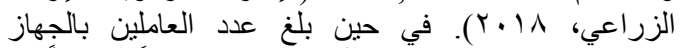

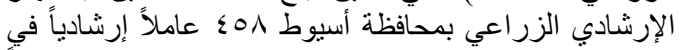

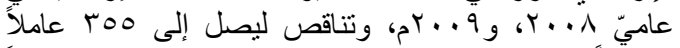

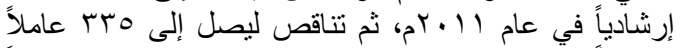

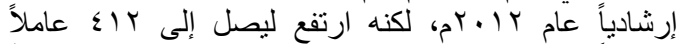

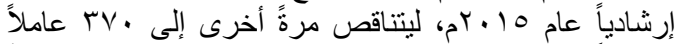

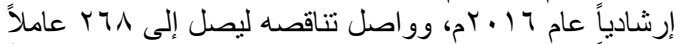

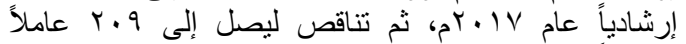

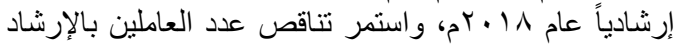




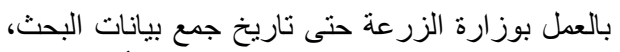

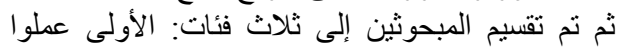

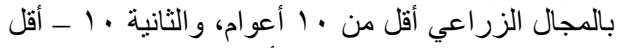

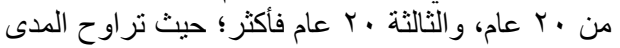

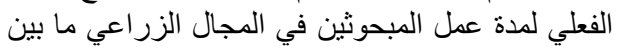

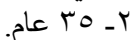

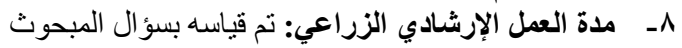

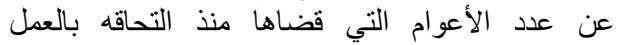

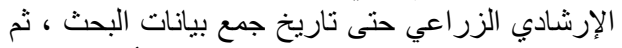

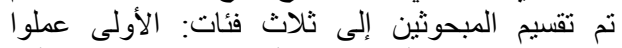

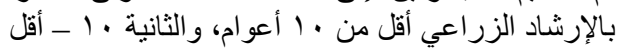

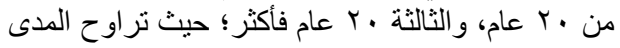

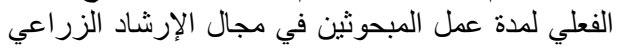

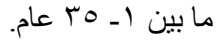

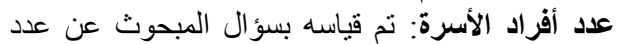

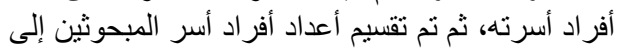

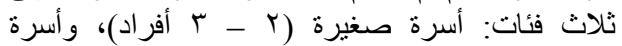

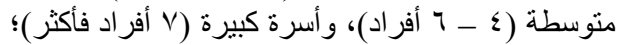

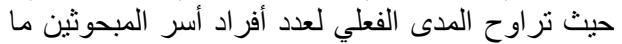

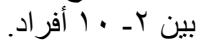
• 1 ـ وجود أفراد متعلمون بالأسرة: تم قياسه بسؤ ال المبحوث

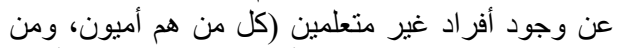

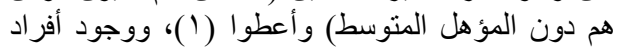

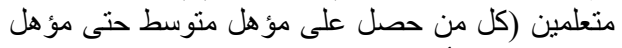
فوق جامعي) وأعطو إ (r) (r).

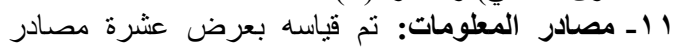

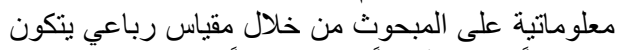

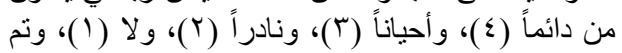

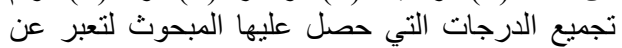

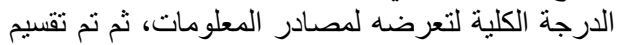

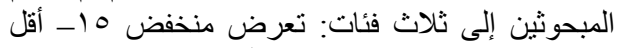

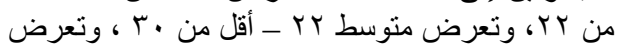

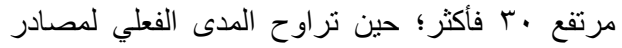

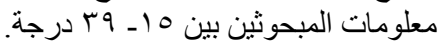

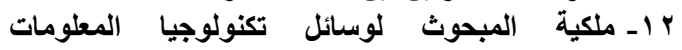

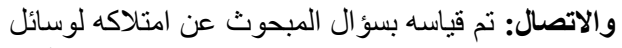

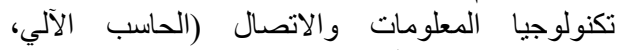

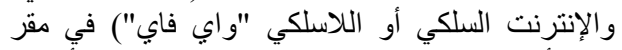

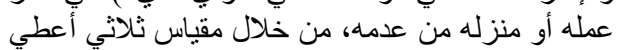

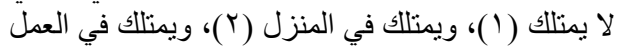

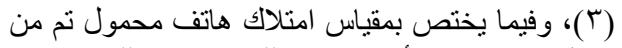

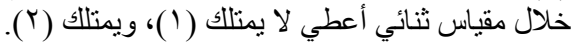

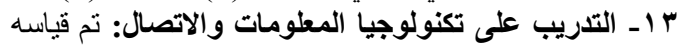

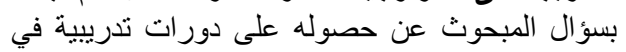

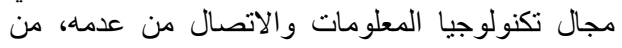
خلال عرض مجموعة من الدورات التدريبية المتعلقة
مجموعة من البنود المقترحة كمنطلبات لاستخدام تكنولوجيا

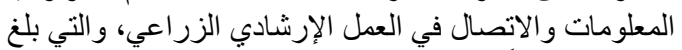

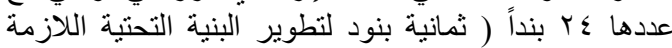

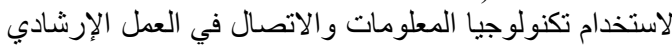

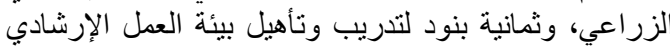

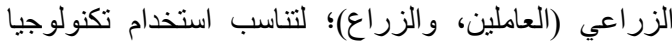

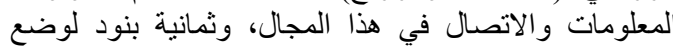

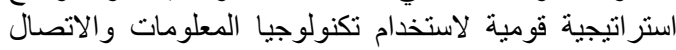

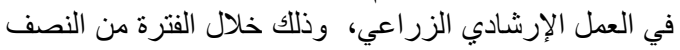

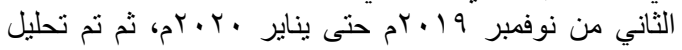

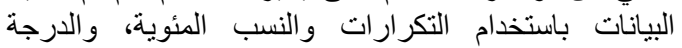

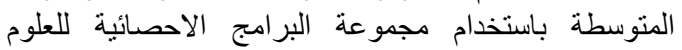
الاجتماعية (SPSS) (ل)

\section{المعالجة الكمية للبيانات}

\section{أولاً: المتغيرات المستقلة:}

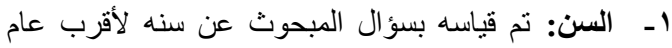

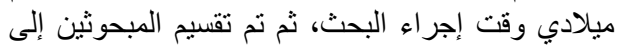

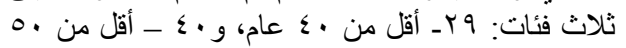

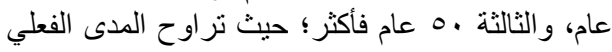

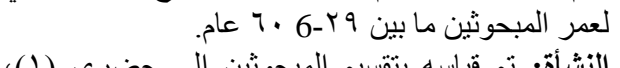

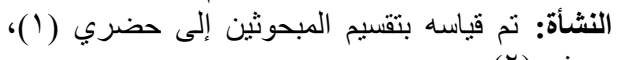
وريفي (r) ) الموني r- - المؤهل الاراسي: تم قياسه بإعطاء المبحوثين الحاصلين

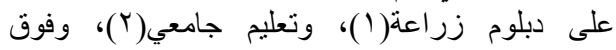

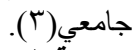
ع - مساحةّة الحيازة الزراعية: تم استخدام الرقم الخام للتعبير

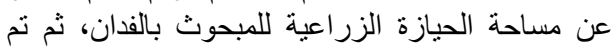

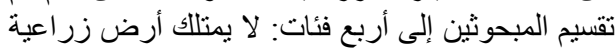

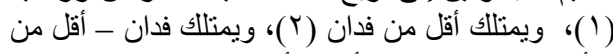

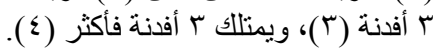

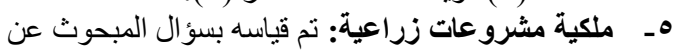

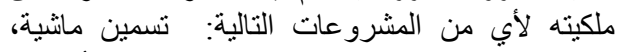

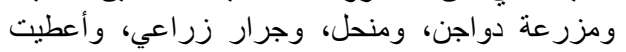

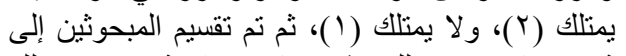

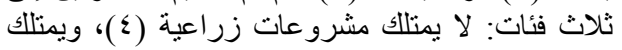

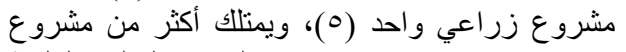

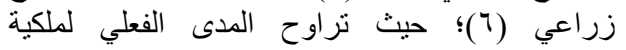

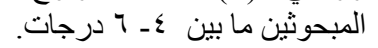

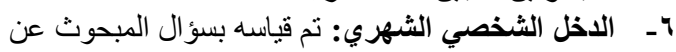

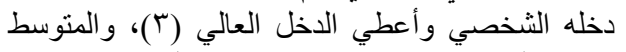

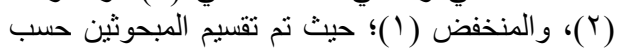

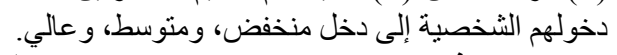

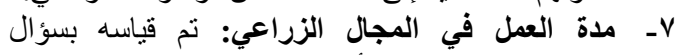

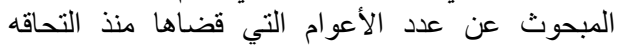


r. تأثير منطلبات استخدام تكنولوجيا المعلومات

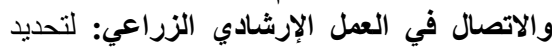

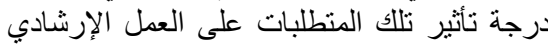

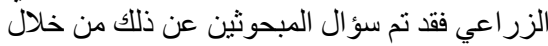

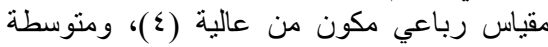

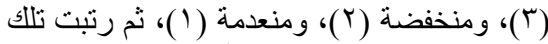

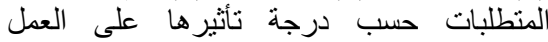
الإرشادي الزراعي ترتيباً تنازلياً وفقاً لاختيارات

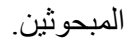

\section{النتائج ومناقشتنها}

أولا: خصائص المبحوثين

تشير البيانات المتعلقة بتوزيع المبحوثين من العاملين بالجهاز

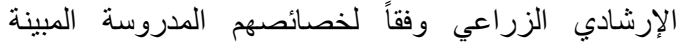

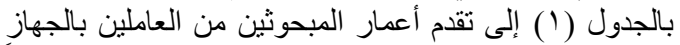

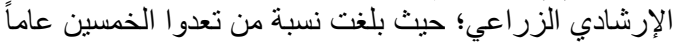

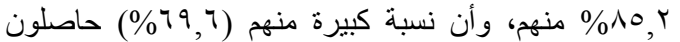

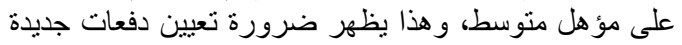

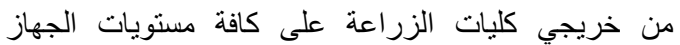

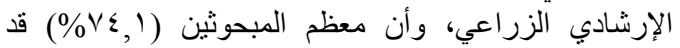

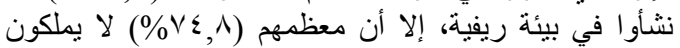

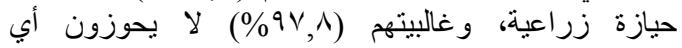

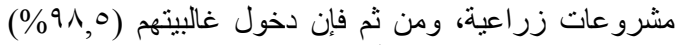

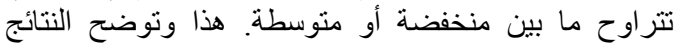

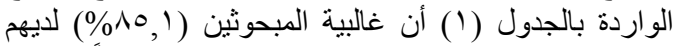

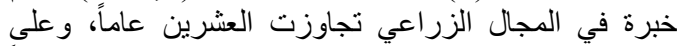

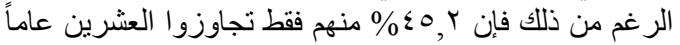

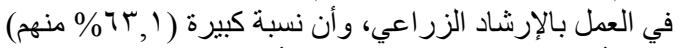

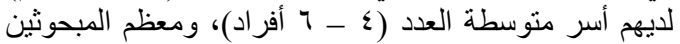

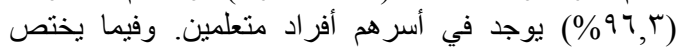

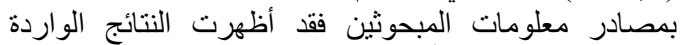

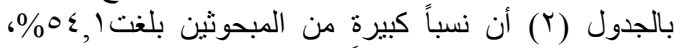

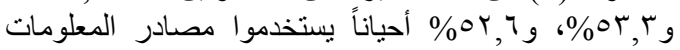

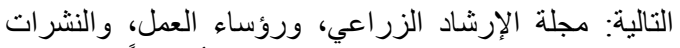

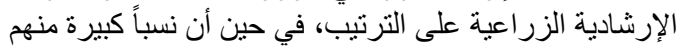

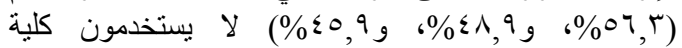

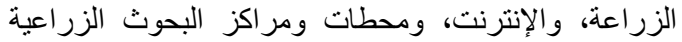

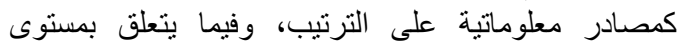

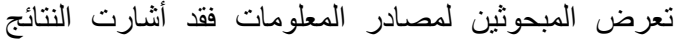

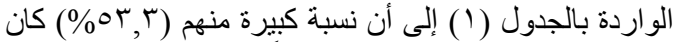
تعرضهم لمصادر المعلومات منوسطاً.
بتكنولوجيا المعلومات و الاتصال (ست دورات) وسؤال

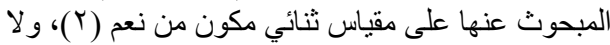

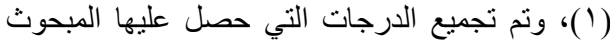

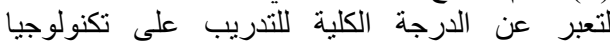
المعلومات والاتصال، ثم تم تقسيم المبحوثين إلى ثلى ثلاث

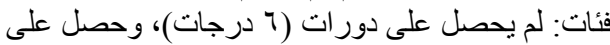

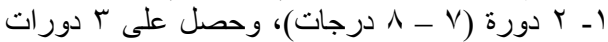
فأكثر(9 درجات فأكثر)؛ حيث تران) وراوح المدى الفعلي

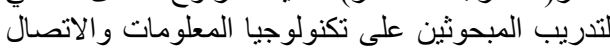

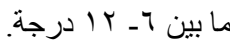

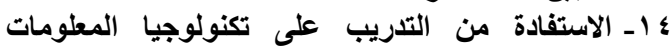

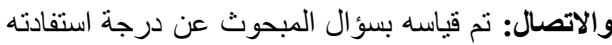

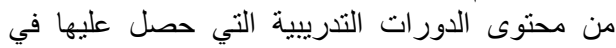

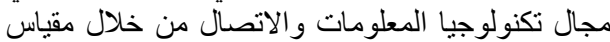

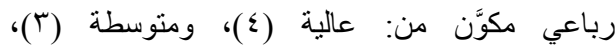

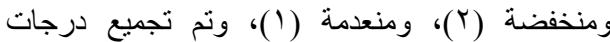

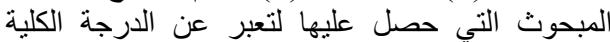

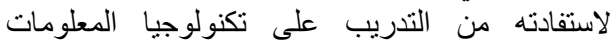
والاتصال، ثم تم تقسيم استفادة المبحوثين إلى ثنى ثلاث

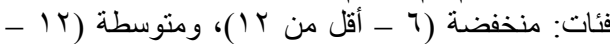

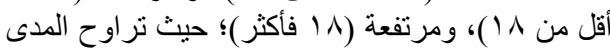

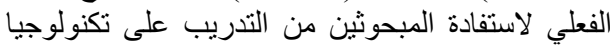
المعلومات و الاتصال ما بين ج- ع ب درجة.

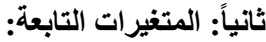

1. متطلبات استخدام تكنولوجيا المعلومات والاتصال

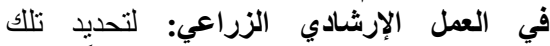
المتطلبات تم صياغة أربعة وعشرين الزين بنداً تندرج

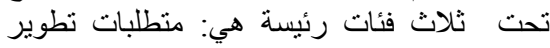

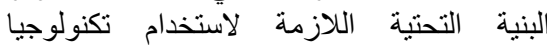

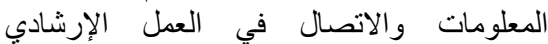

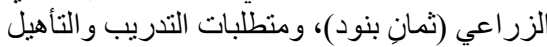

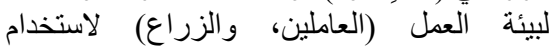

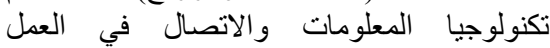

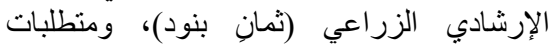

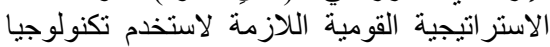

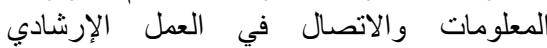

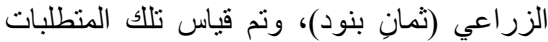

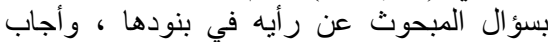

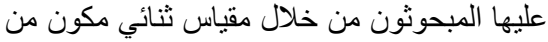

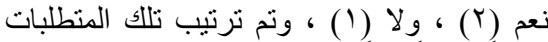
ترنيباً تنتازلياً وفقاً لاختيار ات المبحوثين 
جدول ( (1): التوزيع العددي و النسبي للمبحوثين من العاملين بالجهاز الإرشادي الزر اعي وفقاً لخصائصهم المدروسة.

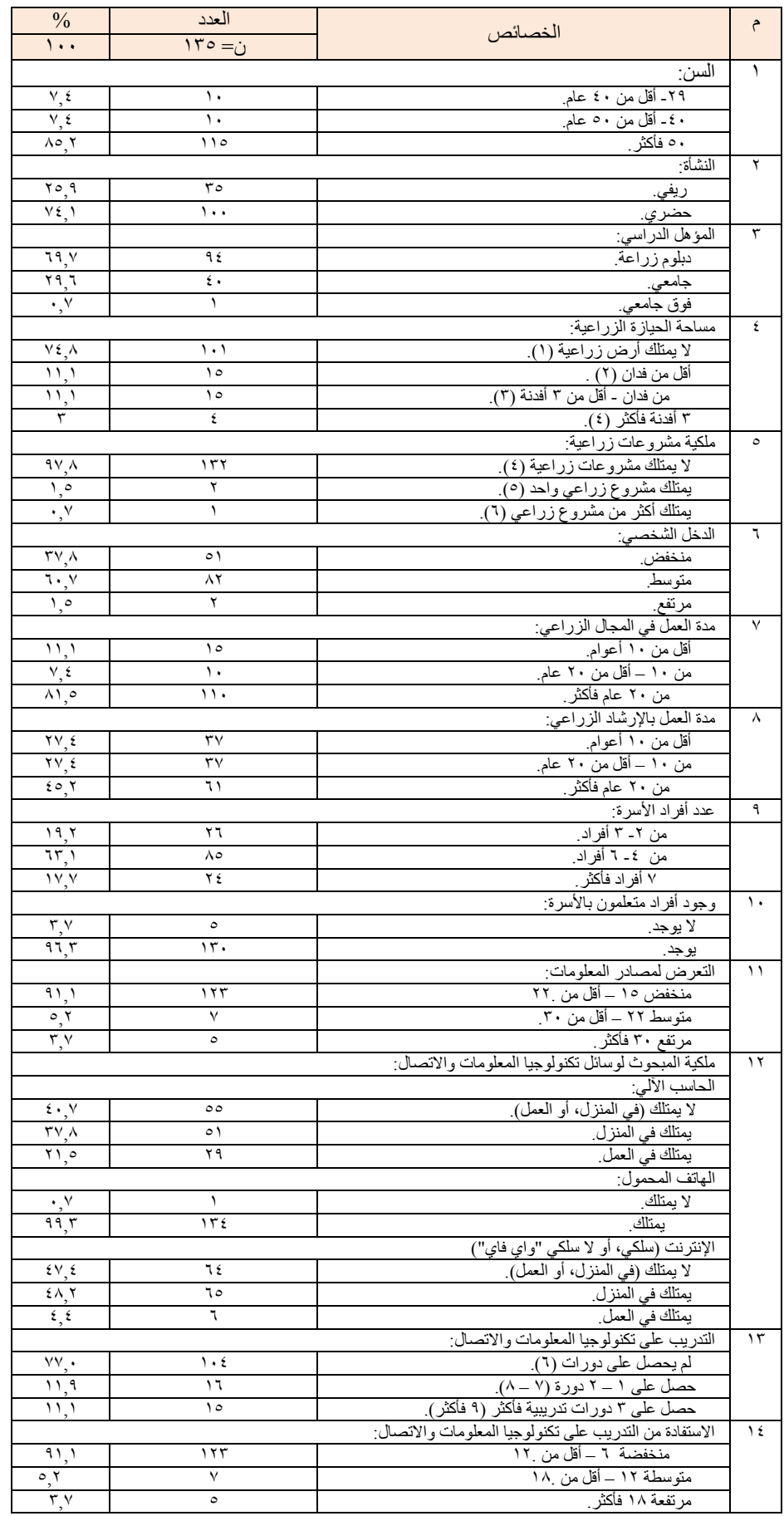

المصدر: استمارات الاستبيان 


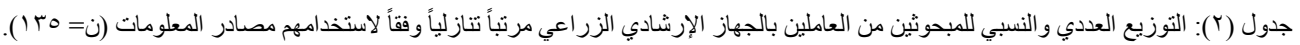

\begin{tabular}{|c|c|c|c|c|c|c|c|c|c|}
\hline \multicolumn{8}{|c|}{ التعرض لمصادر المعلومات } & \multirow{3}{*}{ مصادر المعلومات } & \multirow{3}{*}{ م } \\
\hline \multicolumn{2}{|c|}{$\bar{y}$} & \multicolumn{2}{|c|}{ نادراً } & \multicolumn{2}{|c|}{ أحياناً } & \multicolumn{2}{|c|}{ دائما } & & \\
\hline$\%$ & 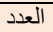 & $\%$ & 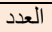 & $\%$ & 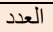 & $\%$ & العدد & & \\
\hline 11,1 & 10 & $17, r$ & rt & $0 \leqslant, 1$ & $\mathrm{vr}$ & 11,0 & ro & مجلة الإرشاد الزراعي & 1 \\
\hline & & $\cdot, \mathrm{V}$ & 1 & or, & VY & $\leqslant 0,9$ & 74 & رؤساء العمل & $r$ \\
\hline $1 \cdot, \varepsilon$ & $1 \varepsilon$ & $I V, \Lambda$ & $T \leqslant$ & or, 1 & VI & $19, r$ & ry & النشر ات الإرشادية الزر اعية & $r$ \\
\hline 1,0 & $r$ & $7, \mathrm{~V}$ & 9 & 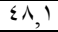 & 70 & $\varepsilon r, v$ & 09 & زملاء العمل & $\varepsilon$ \\
\hline$r r, \cdot$ & rI & $r 0, r$ & $r \varepsilon$ & $\varepsilon 1,0$ & 07 & $1 \cdot, \varepsilon$ & $1 \varepsilon$ & البر امج التليفزيونية الزر اعية & 0 \\
\hline 11,1 & 10 & $Y 7, Y$ & ry & $r \Lambda, 0$ & or & Tr,, & Tr & الدورات التدريبية & 7 \\
\hline$r \wedge, 1$ & rA & $r 9,7$ & $\varepsilon \cdot$ & $r q, r$ & $\sum 9$ & 0,9 & $\Lambda$ & البرامج الإذاعية الزراعية & $\mathrm{v}$ \\
\hline$\leqslant 0,9$ & TY & $T r, Y$ & re & TY,Y & $r \cdot$ & $\wedge, 1$ & 11 & مر اكز ومحطات البحوث الزر اعية & $\Lambda$ \\
\hline$\varepsilon \wedge, 9$ & 77 & $I V, \Lambda$ & $T \varepsilon$ & $r 1,0$ & rq & 11,9 & 17 & 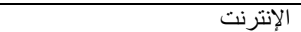 & 9 \\
\hline $07, r$ & $\mathrm{VT}$ & $19, r$ & ry & $19, r$ & ry & $0, r$ & $\mathrm{~V}$ & كلبة الزر اعة & 1. \\
\hline
\end{tabular}

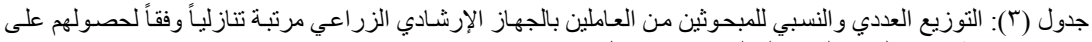

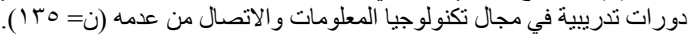

\begin{tabular}{|c|c|c|c|c|c|}
\hline \multicolumn{4}{|c|}{ الحصول على دورات تدريبية } & \multirow{3}{*}{ الدورات التدريبية } & \multirow{3}{*}{ ? } \\
\hline \multicolumn{2}{|c|}{$\bar{\nu}$} & \multicolumn{2}{|c|}{ نعم } & & \\
\hline$\%$ & العدد & $\%$ & العدد & & \\
\hline$\%$ & العدد & $\%$ & العدد & استخدام الجداول الإلكترونية (برنامج إكسيل) & 1 \\
\hline $95, \Gamma$ & $1 \times 4$ & $7, \mathrm{Y}$ & 9 & إرسال واستقبال رسائل إلكترونية عبر البريد الإلكتروني (الإيميل) & r \\
\hline $9 \cdot, \varepsilon$ & TYY & 9,7 & 14 & إعداد وكتابة تقرير بالكمبيوتر باستخدام برنامج وورد & $r$ \\
\hline$\wedge 9,7$ & $|r|$ & $1 \cdot, \varepsilon$ & $1 \varepsilon$ & 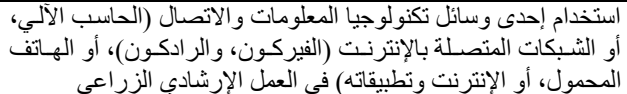 & $\varepsilon$ \\
\hline$\wedge \wedge, 9$ & Tr. & 11,1 & 10 & إعداد وحفظ صفحات من الإنترنت & 0 \\
\hline$\lambda \wedge, 1$ & 119 & 11,9 & 17 & التفاعل مع الآخرين عبر غرف الدردشة (الثات) & 7 \\
\hline
\end{tabular}

جدول (ع): أعداد ونسب المبحوثين من العاملين بالجهاز الإرشادي الزر اعي مرتبة تنتازلياً وفقاً لاستفادتهم من التدريب في مجال تكنولوجيا المعلومات

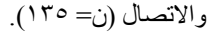

\begin{tabular}{|c|c|c|c|c|c|c|c|c|c|}
\hline \multicolumn{8}{|c|}{ الاستفادة من التذريب } & \multirow{3}{*}{ 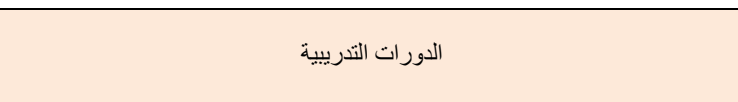 } & \multirow{3}{*}{ s } \\
\hline \multicolumn{2}{|c|}{ 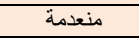 } & \multicolumn{2}{|c|}{ منخفضة } & \multicolumn{2}{|c|}{ متوسطة } & \multicolumn{2}{|c|}{ عالية } & & \\
\hline$\%$ & العدد & $\%$ & العدد & $\%$ & العدد & $\%$ & العدد & & \\
\hline 91,9 & TY & $r, Y$ & $\circ$ & 1,0 & r & $r$, & $\varepsilon$ & | استخدام الجداول الإلكترونية (برنامج إكسيل) & 1 \\
\hline 91,1 & Trt & $0, Y$ & V & $\cdot, \mathrm{v}$ & 1 & $r$ & $\varepsilon$ & إرسال واستقبال رسائل إلكترونية عبر البريد الإلكتروني (الإيميل) & r \\
\hline$\wedge \wedge, 9$ & Tr. & $r, \mathrm{r}$ & $\circ$ & $r$, & $\varepsilon$ & $\varepsilon$, & 7 & | إعداد وكتابة تقرير بالكمبيوتز باستخدام برنامج وورد & $r$ \\
\hline$\wedge, q$ & Kr. & $r, r$ & $r$ & $0, r$ & V & $r, v$ & 0 & 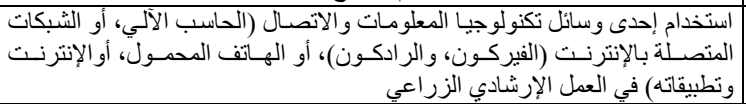 & $\varepsilon$ \\
\hline$\lambda \wedge, 1$ & 119 & $r, Y$ & $r$ & $\mathrm{~V}, \varepsilon$ & $1 \cdot$ & $r, r$ & $r$ & إعداد وحفظ صفحات من الإنترنت & 0 \\
\hline$\Delta r, v$ & 114 & $\varepsilon, \varepsilon$ & 7 & 0,9 & $\Lambda$ & 0,9 & $\Lambda$ & التفاعل مع الآخرين عبر غرف الدردشة (الثـات) & 7 \\
\hline
\end{tabular}

وسائل تكنولوجيا المعلومات والاتصال للعاملين بالجهاز

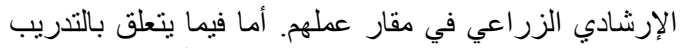

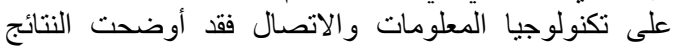

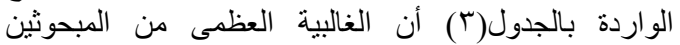

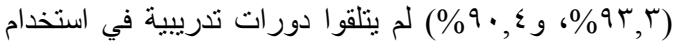

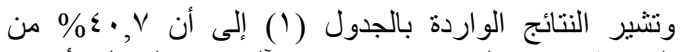

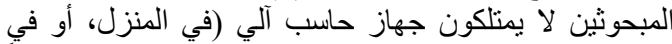

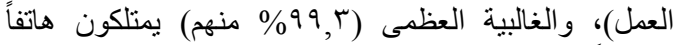

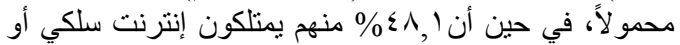

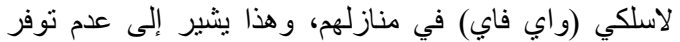


وافقوا على البنود الثمانية المقترحة لتطوير البنية التحتية

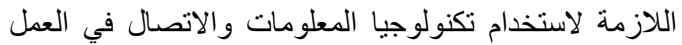

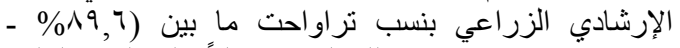

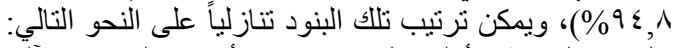

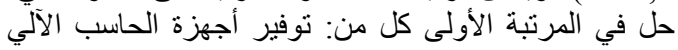

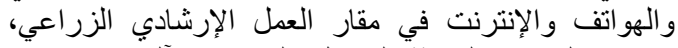

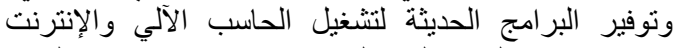
(\%乏,^)

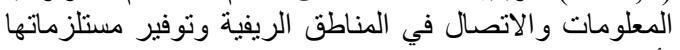

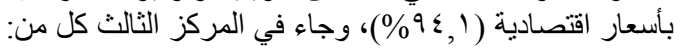

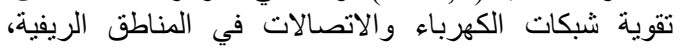

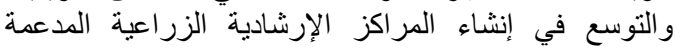

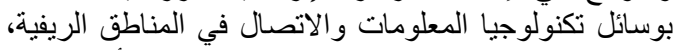

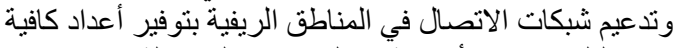

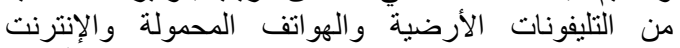

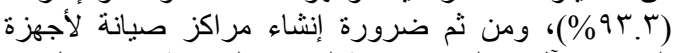

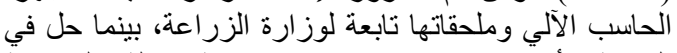
المرتبة الأخيرة بند توفير وحدات إرشادية منتقلة على هلى هيئة سيارة بها جهاز حاسب آلي وملحقاته و إنترنت لانب سلكي (واي

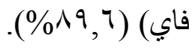

برنامج إنشاء الجداول الإلكترونية (Excel)، و إرسال واستقبال رسائل إلكترونية عبر البريد الإلكتروني (E-mail)

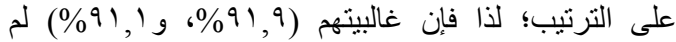
يستفيدوا من التدريب على هاتين المهارتين اللازمتين لاستخدام

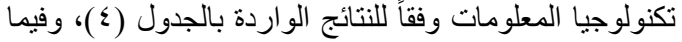

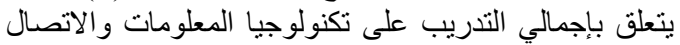

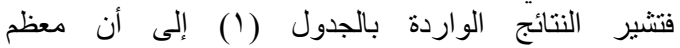

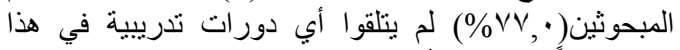

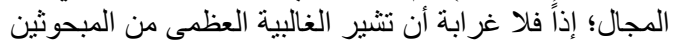

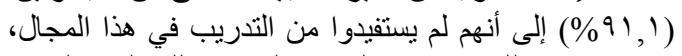
ويستنتج من ذلك انخفاض الجانب التهان التدريبي للعاملين بالجهاز

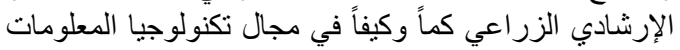

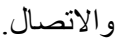

\section{ثانيا: متطلبات استخدام تكنولوجيا المعلومات والاتصال}

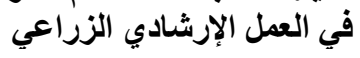

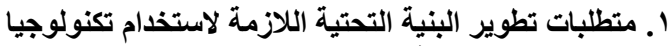

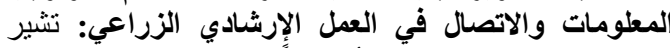
النتائج الواردة بالجدول (0) أن نسباً مرتفعة من المبحوثين الزئ قدير

جدول (0): التوزيع العددي و النسبي للمبحوثين من العاملين بالجهاز الإرشادي الزراعي واعثياً لآر ائهم في منطلبات تطوير البنية التحتية اللازمة لاستخدام

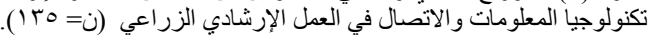

\begin{tabular}{|c|c|c|c|c|c|}
\hline \multicolumn{4}{|c|}{ رأي المبحوثين } & \multirow{3}{*}{ 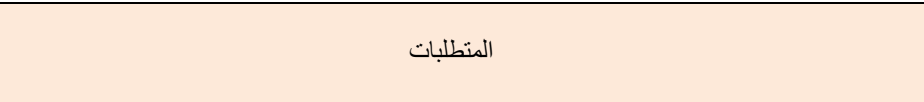 } & \multirow{3}{*}{ b } \\
\hline \multicolumn{2}{|c|}{ غير مو افق } & \multicolumn{2}{|c|}{ مو افق } & & \\
\hline$\%$ & العدد & $\%$ & العدد & & \\
\hline $0, r$ & $\mathrm{~V}$ & $9 \leq, \wedge$ & $1 Y \Lambda$ & توفير البر امج الحديثة لتشغيل الحاسب الآلي و الإنترنت & 1 \\
\hline $0, r$ & $\mathrm{~V}$ & $9 \varepsilon, \wedge$ & IYA & توفير أجهزة الحاسب الآلي، و الهو اتف، والإنترنت في مقار العمل الإرشادي الزراعي & $Y$ \\
\hline 0,9 & $\Lambda$ & $9 \leq, 1$ & ITV & دعم استخدام تكنولوجيا المعلومات و الاتصال في المناطق الريفية، وتوفير مستلز ماتها بأسعار اقتصادية & $r$ \\
\hline $7, \mathrm{~V}$ & 9 & $94, r$ & $1 \times 4$ & تقوية شبكات الكهرباء و الاتصالات في المناطق الريفية & $\varepsilon$ \\
\hline $7, \mathrm{~V}$ & 9 & $94, r$ & $1 \times 4$ & التوسع في إنشاء المر اكز الإرشادية المدعمة بوسائل تكنولوجيا المعلومات و الاتصال في المناطق الريفية & 0 \\
\hline 7,7 & 9 & $94, r$ & $1 \times 4$ & تلدعميم شبكات الاتصالات في المناطق الريفية من خلال توفير أعداد كافية من التلنفونات الارضية، و الهو اتف & 7 \\
\hline $\mathrm{V}, \xi$ & 1. & 94,7 & 1ro & إنشاء مر اكز صبانة لأجهزة الحاسب الآلي وملحقاتها تابعة لوزر اة الزر اعة & $\mathrm{v}$ \\
\hline $7, \mathrm{Y}$ & 9 & 19,7 & $T M$ & توفير وحدات إرشادية متنقلة على هيئة سيارة بها حاسب آلي وملحقاته، ونت لا سلكي (واب فاي) & $\wedge$ \\
\hline
\end{tabular}

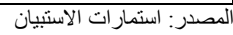

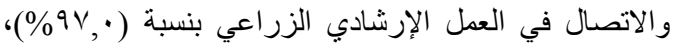

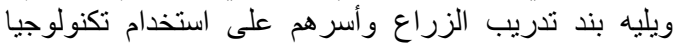

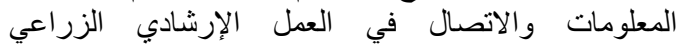

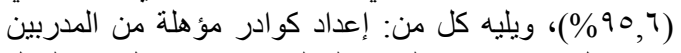

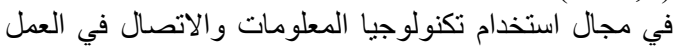

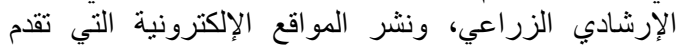

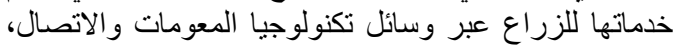

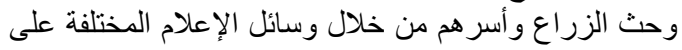

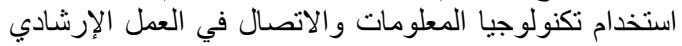

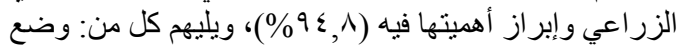
وتنفيذ برامج تدريية حديثة لتنريب العاملين بالإرشاد r. متطلبات تدريب وتأهيل بيئة العمل الإرشادي الزراعي

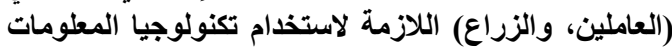

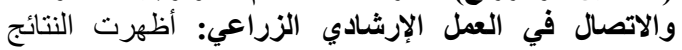

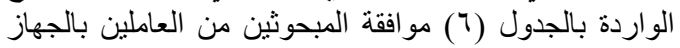

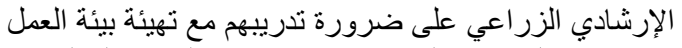

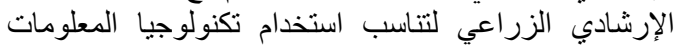

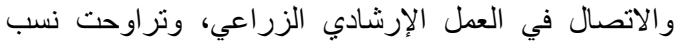

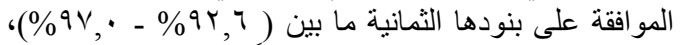

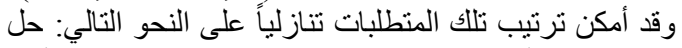

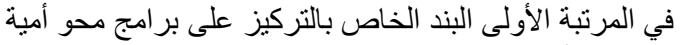

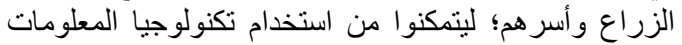


المرتبة الأخيرة بند بتشجيع القطاع الخاص ومؤسسات

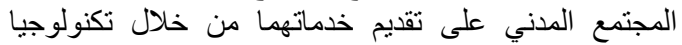

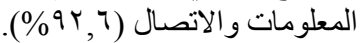

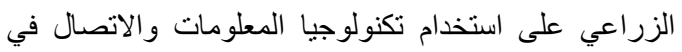

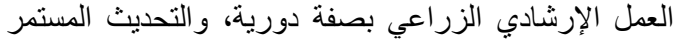

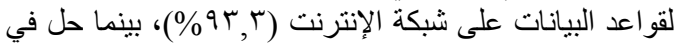

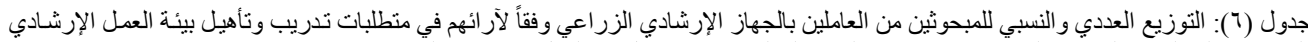

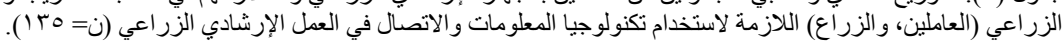

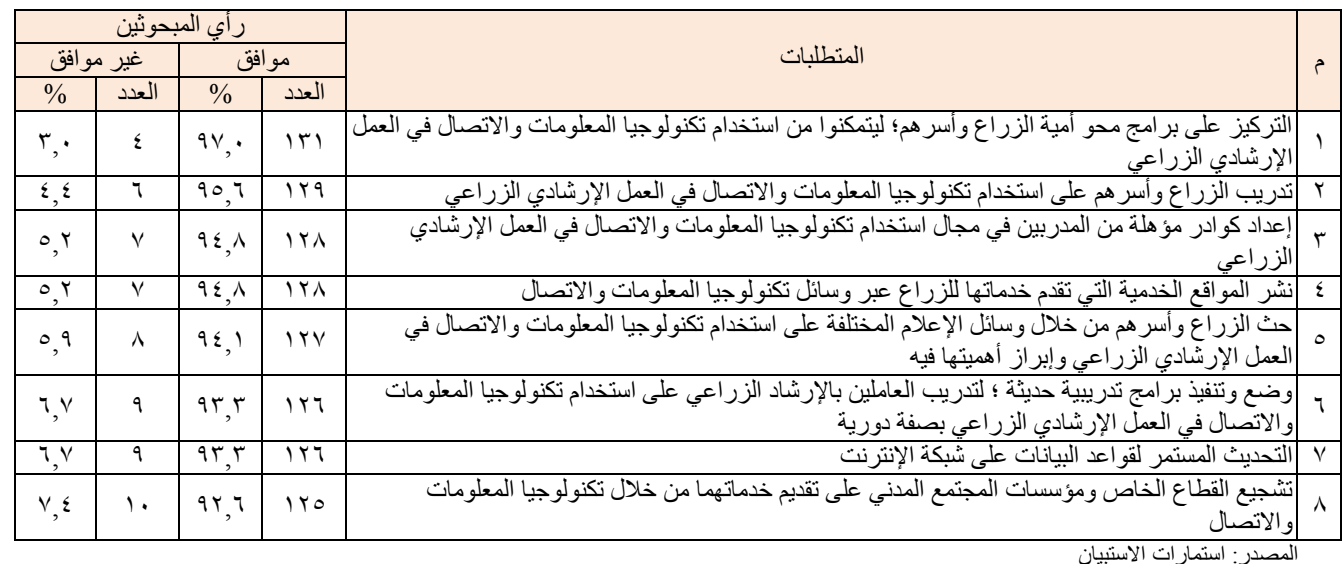

استراتيجية قومية لاستخدام تكنولوجيا المعلومات والاتصال الزمال

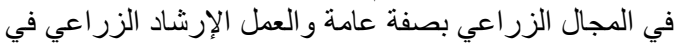

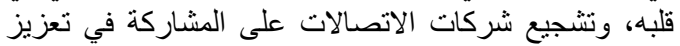

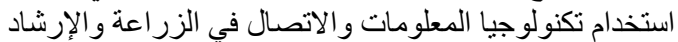

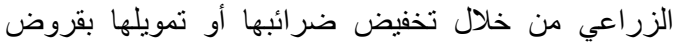

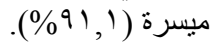

ثالثا: درجة تأثير متطلبات استخدام تكنولوجيا

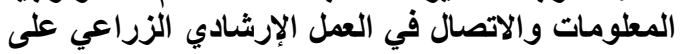
العمل الإرشادي الزراعي

ا ـ آراء المبحوثون من العاملين بالجهاز الإرشادي الزراعي

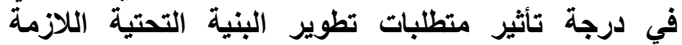

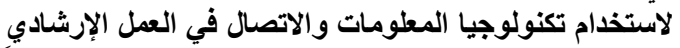

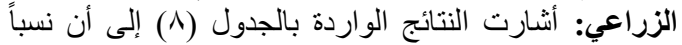

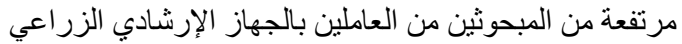

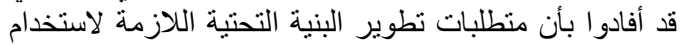

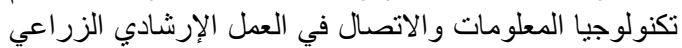

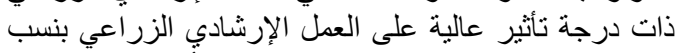

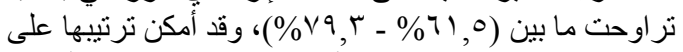

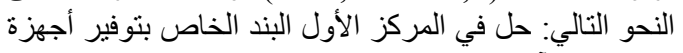

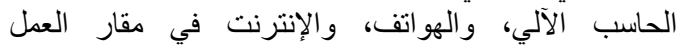

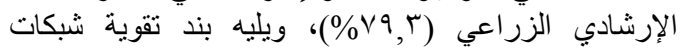

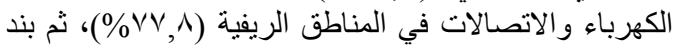

r. متطلبات الاستراتيجية القومية اللازمة لاستخدام

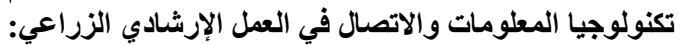

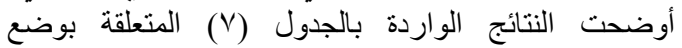

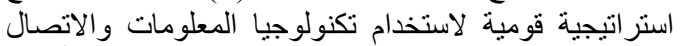

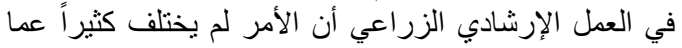

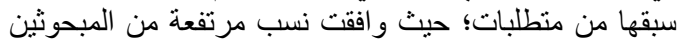

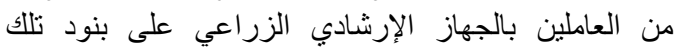

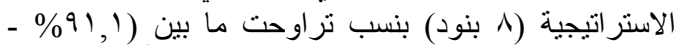

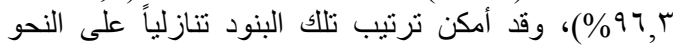

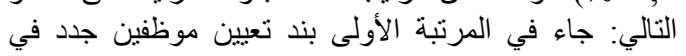

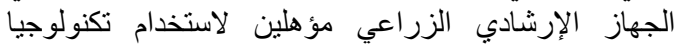

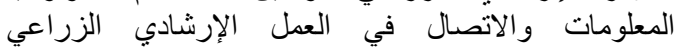

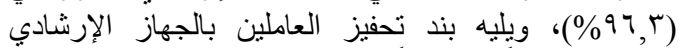

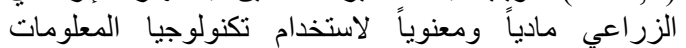

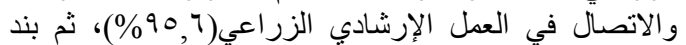

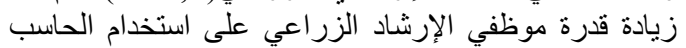

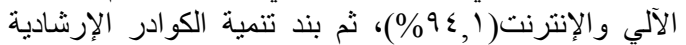

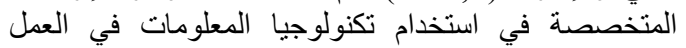

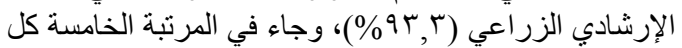

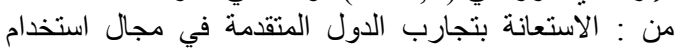

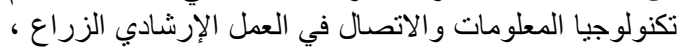

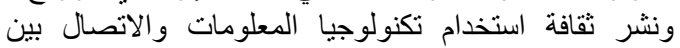

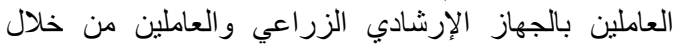

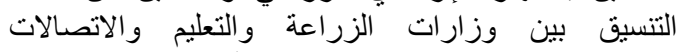

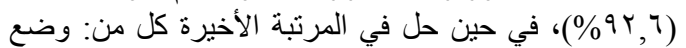


الأرضية والمحمولة والإنترنت، وتوفير وحدات إرشادية

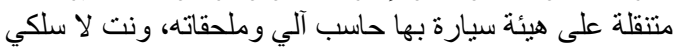

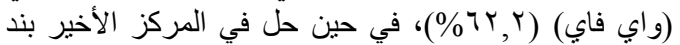

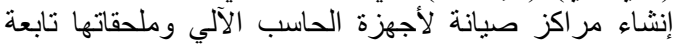

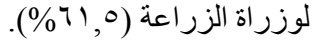

التوسع في إنشاء المراكز الإرشادية المدعمة بوسائل

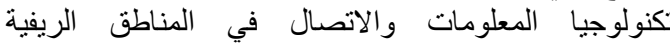

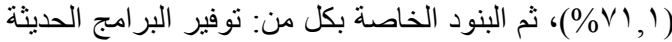

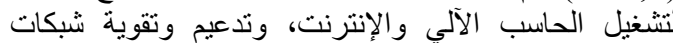
الاتصالات في المناطق الريفية بأعداد كافية من الأنرونة

جدول (V): التوزيع العددي و النسبي للمبحوثين من العاملين بالجهاز الإرشادي الزراعي وفقاً لآر ائهم في متطلبات الاستر اتيجية القومية اللازمة لاستخدام

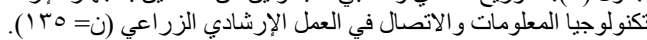

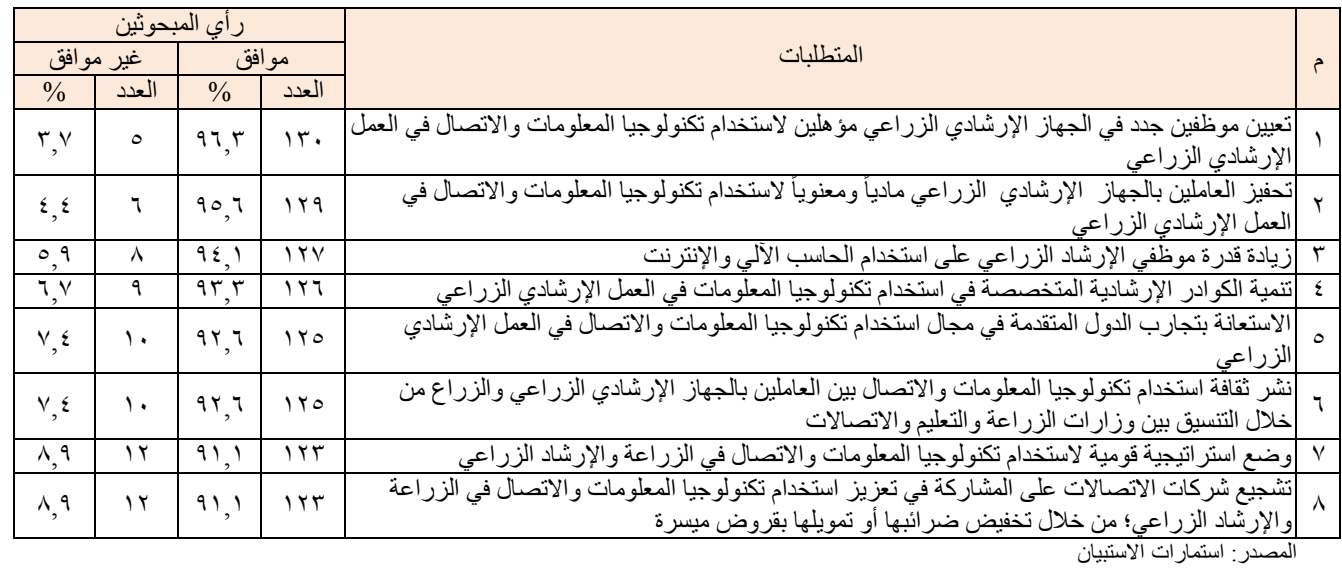

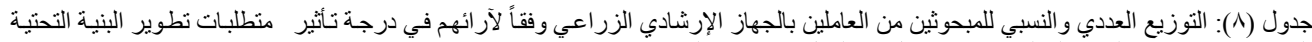

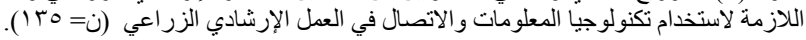

\begin{tabular}{|c|c|c|c|c|c|c|c|c|c|}
\hline \multicolumn{8}{|c|}{ درجة تأثير المتطلبات } & \multirow{3}{*}{ المتطلبات } & \multirow{3}{*}{ ? } \\
\hline \multicolumn{2}{|c|}{ منعدمة } & \multicolumn{2}{|c|}{ منخفضة } & \multicolumn{2}{|c|}{ متوسطة } & \multicolumn{2}{|c|}{ عالية } & & \\
\hline$\%$ & 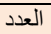 & $\%$ & 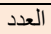 & $\%$ & 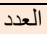 & $\%$ & 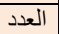 & & \\
\hline r, & $\varepsilon$ & $r, \mathrm{~V}$ & 0 & $1 \leq, 1$ & 19 & vq,r & $1 \cdot v$ & 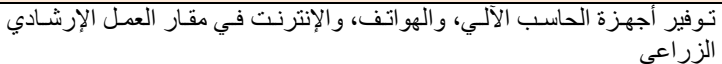 & 1 \\
\hline $0, Y$ & V & $r, r$ & $r$ & $1 \leqslant, \wedge$ & Y. & $V \vee, \wedge$ & 1.0 & تقوية شبكات الكهرباء و الاتصالات في المناطق الريفية & r \\
\hline r, , & 0 & $0, r$ & $\mathrm{~V}$ & $r \cdot, \cdot$ & rV & $\vee 1,1$ & 97 & 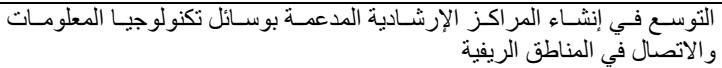 & $r$ \\
\hline$\varepsilon, \varepsilon$ & 7 & $7, \mathrm{~V}$ & 9 & $r V, T$ & ry & $T Y, Y$ & $\wedge \varepsilon$ & توفير البر امج الحديثة لتشغيل الحاسب الآلي والإنترنت & $\varepsilon$ \\
\hline 0,9 & $\wedge$ & 0,9 & $\wedge$ & ro, 9 & ro & $7 r, Y$ & $\Lambda \varepsilon$ & 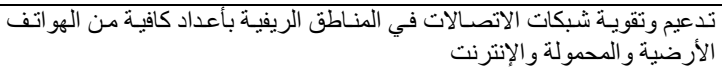 & 0 \\
\hline $7, \mathrm{~V}$ & 9 & 1,9 & it & $r$ r, & r. & $T r, r$ & $\Lambda \varepsilon$ & توفير وحدات إرشادية متنقلة على هيئة سبارة بها حاسب آلي وملحقاته، ونت لا & 7 \\
\hline$\varepsilon, \varepsilon$ & 7 & 0,9 & $\wedge$ & $r \wedge, 1$ & 众 & 71,0 & N & 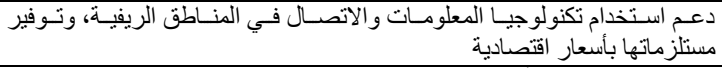 & V \\
\hline T, , & 0 & $V, \Sigma$ & $1 \cdot$ & rV,, & rV & 71,0 & NT & إنشاء مر اكز صيانة لاجهزة الحاسب الآلي وملحقاتها تابعة لوزر اة الزر اعة & $\Lambda$ \\
\hline
\end{tabular}

المعلومات والاتصال ذات تأثثير عال على العمل الإرشادي

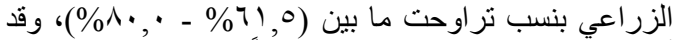

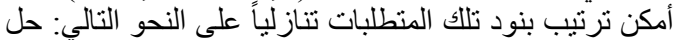

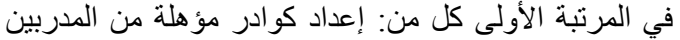

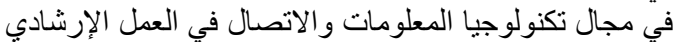

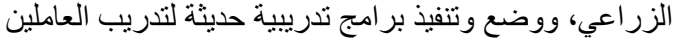
في الجهاز الإرشادي الزراعي برايج على استخدام تكنولوجيا
ب. آراء المبحوثون من العاملين بالجهاز الإرشادي الزراعي

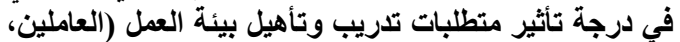

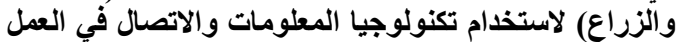

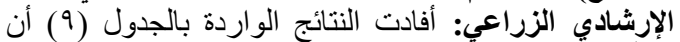

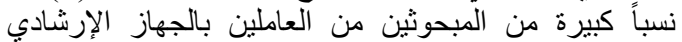

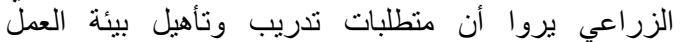
الإرشادي الزراعي (العاملين، والزراع) لاستخدام تكنولوجيا 


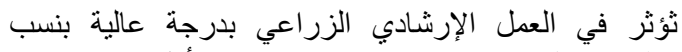

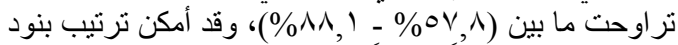

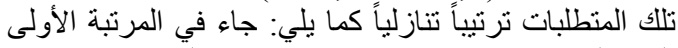

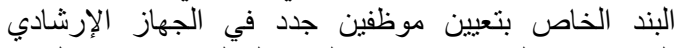

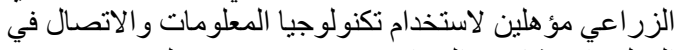

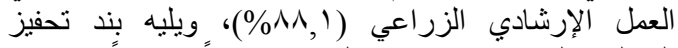

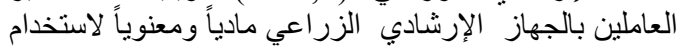

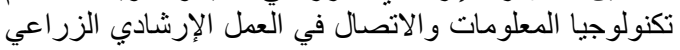

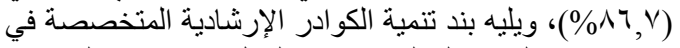

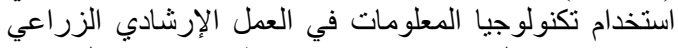

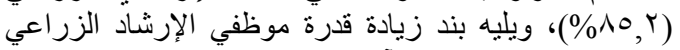

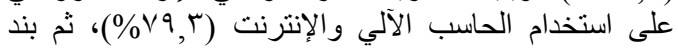
الاستعانة بتجارب الدول المتقدمة في مجال استخدام تكنولوجيا لإلونيا

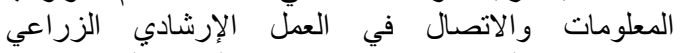

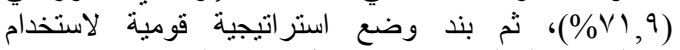

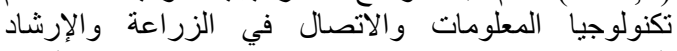

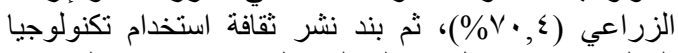

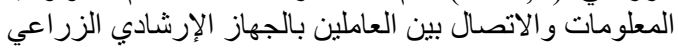

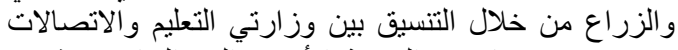

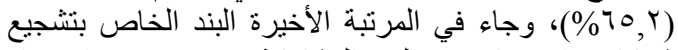

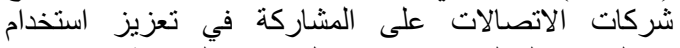

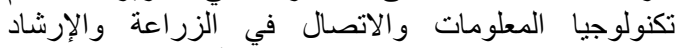

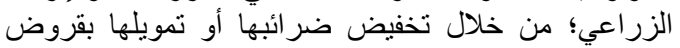

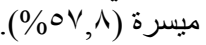

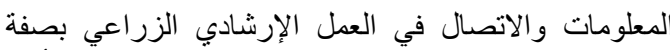

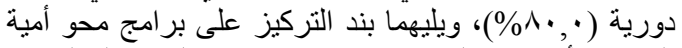

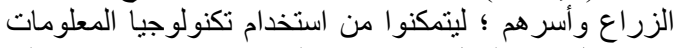

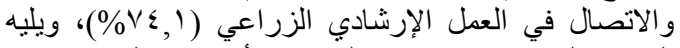

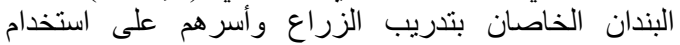

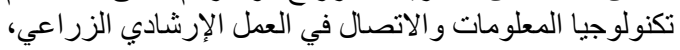

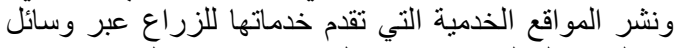

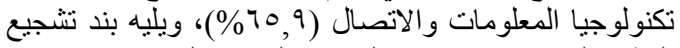
القطاع الخاص ومؤسسات المجتمع المدني على ولى تقديم خدماتهما

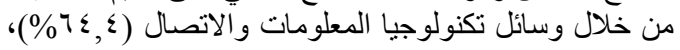

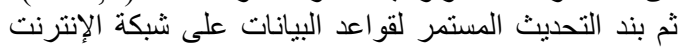

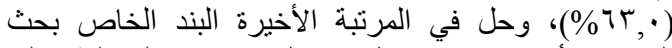

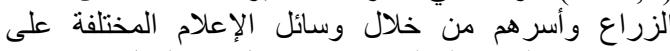

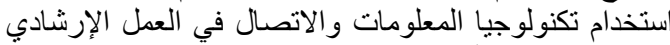

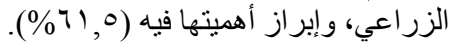

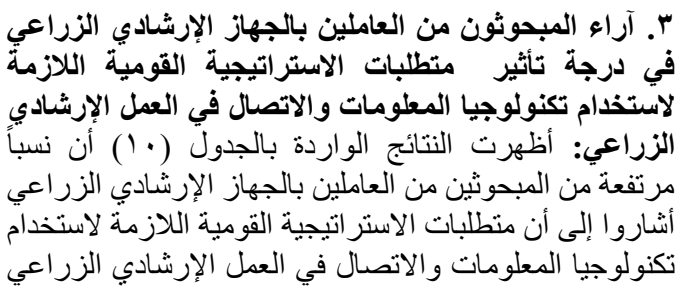

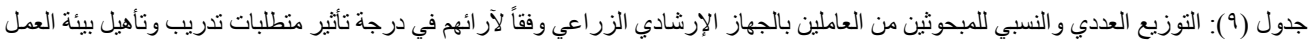

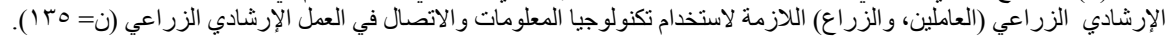

\begin{tabular}{|c|c|c|c|c|c|c|c|c|c|}
\hline \multicolumn{8}{|c|}{ درجة تأثير المنطلبات } & \multirow{3}{*}{ المنطلبات } & \multirow{3}{*}{5} \\
\hline \multicolumn{2}{|c|}{ منعدمة } & \multicolumn{2}{|c|}{ منخفة } & \multicolumn{2}{|c|}{ متوسطة } & \multicolumn{2}{|c|}{ عالية } & & \\
\hline$\%$ & العدد & $\%$ & العدد & $\%$ & العدد & $\%$ & العدد & & \\
\hline$r, v$ & 0 & $\cdot, \mathrm{V}$ & 1 & 10,7 & YI & $\wedge \cdot, \cdot$ & $1 \cdot 1$ & العمل الإرشادي كو ادر مؤهلة من الزر اعدربين في مجـال تكنولوجيـا المعلومـات والاتصسال في & 1 \\
\hline $0, r$ & V & $\cdot, \mathrm{V}$ & 1 & $1 \leqslant, 1$ & 19 & $\wedge \cdot, \cdot$ & $1 \cdot 1$ & 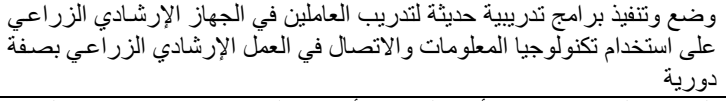 & T \\
\hline$r, v$ & 0 & $r, r$ & r & $r \cdot, \cdot$ & rV & $v \leqslant, 1$ & $1 \ldots$ & 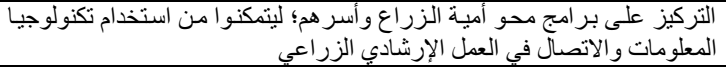 & $r$ \\
\hline $0, r$ & V & $r$, & $\varepsilon$ & ro, 9 & ro & 70,9 & 19 & الإرشاديب الزراع وأسر هم على استخدام تكنولوجيا المعلومسات والاتصـال في العمل & $\varepsilon$ \\
\hline $0, r$ & V & $r$, & $\varepsilon$ & $r o, q$ & ro & 70,9 & 19 & و الاتصر الموالقع الخدمية التي تقدم خدماتها للزراع عبر وسـائل تكنولوجيا المعلومـات & 0 \\
\hline$\varepsilon, \varepsilon$ & 7 & 9,7 & $1 T$ & $r 1,0$ & rq & $7 \leq, \leq$ & AV & 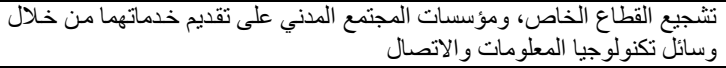 & 7 \\
\hline $7, \mathrm{~V}$ & 9 & $0, Y$ & $\mathrm{~V}$ & ro,, & T纟 & $\pi$ & 10 & التحديث المستمر لقو اعد البيانات على شبكة الإنترنت & V \\
\hline 0,9 & $\wedge$ & $0, r$ & V & $r v, \varepsilon$ & $r v$ & 71,0 & זה & 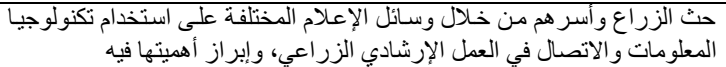 & $\Lambda$ \\
\hline
\end{tabular}




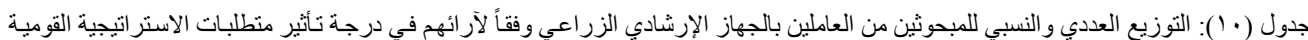

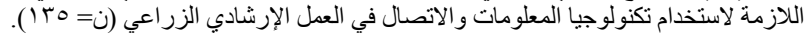

\begin{tabular}{|c|c|c|c|c|c|c|c|c|c|}
\hline \multicolumn{8}{|c|}{ درجة تأثير المنطلبات } & \multirow{3}{*}{ المنطلبات } & \\
\hline \multicolumn{2}{|c|}{ 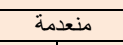 } & \multicolumn{2}{|c|}{ منخفضة } & \multicolumn{2}{|c|}{ 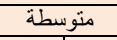 } & \multicolumn{2}{|c|}{ عالية } & & ? \\
\hline$\%$ & 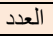 & $\%$ & 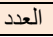 & $\%$ & 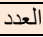 & $\%$ & 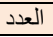 & & \\
\hline$r, Y$ & $r$ & $\cdot, \mathrm{V}$ & 1 & 1,9 & Ir & $\wedge \wedge, 1$ & 119 & 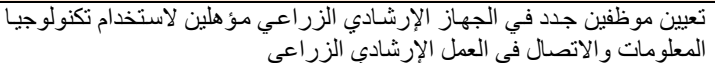 & $T$ \\
\hline$r, r$ & $r$ & $r, r$ & $r$ & 1,9 & Ir & ᄉ & $11 \mathrm{~V}$ & 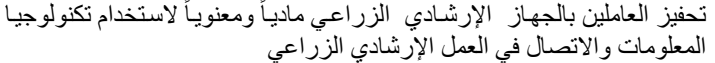 & r \\
\hline r,, & 0 & $r, v$ & 0 & $\vee, \varepsilon$ & 1. & $10, r$ & 110 & تتنمية الكو ادر الإرشادية المتخصصة في استخدام تكنولوجيا المعلومـات في العمل & $r$ \\
\hline r, & 0 & 1,0 & r & 10,7 & Y) & $\mathrm{vq}, \mathrm{r}$ & $1 \cdot \mathrm{V}$ & زيادة قدرة موظفي الإرشاد الزر اعي على استخدام الحاسب الآلي و الإنترنت & $\varepsilon$ \\
\hline$\varepsilon, \varepsilon$ & 7 & $r$, & $\varepsilon$ & $r \cdot, Y$ & $r \wedge$ & V), 9 & $9 V$ & 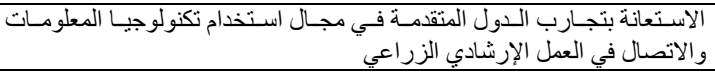 & 0 \\
\hline$v, \varepsilon$ & 1. & $\varepsilon, \varepsilon$ & 7 & $I V, \lambda$ & $r \varepsilon$ & $V \cdot, \varepsilon$ & 90 & و والإرشعاد الزتر اتيجية قومية لاستخدام تكنولوجيا المعلومـات و الاتصـال في الزراعة & 7 \\
\hline$v, \xi$ & 1. & $\varepsilon, \varepsilon$ & 7 & $r r$, & r & $70, r$ & $\wedge \wedge$ & 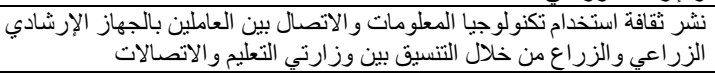 & v \\
\hline$v, \varepsilon$ & 1. & 11,9 & 17 & $r r$, & r & ov,, 1 & $v \wedge$ & 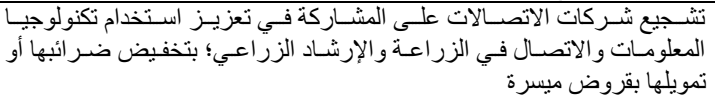 & $\Lambda$ \\
\hline
\end{tabular}

الزر اعية الموجودة حالياً ، و التوسع في إنشاء المزيد منها مع العائ

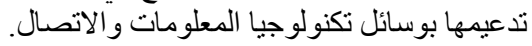

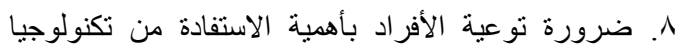

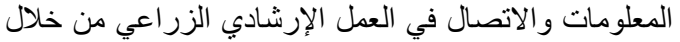
وسائل الإعلام المختلفة.

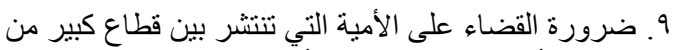

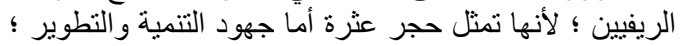

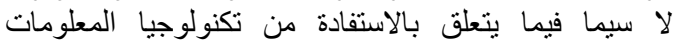

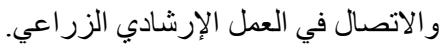

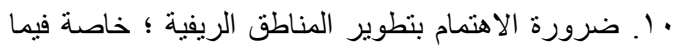

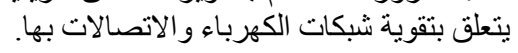

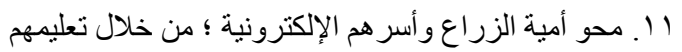

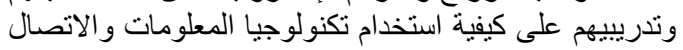
في العمل الإرشادي الزرئي.

\section{قائمة المراجع أولاً: المراجع باللغة العربية المراية}

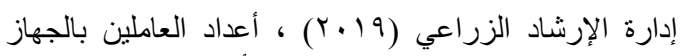

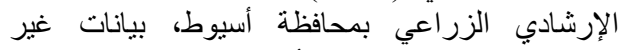

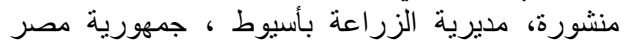
العربية.

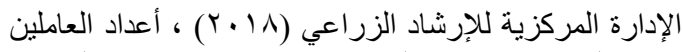

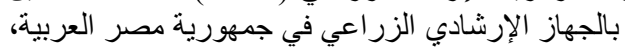

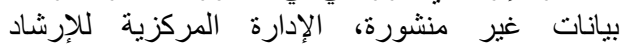

\section{التوصيات}

في ضوء ما توصل إليه البحث من نتائج بمكن التوصية بما يلي: في ا ضرورة تعيين دفعات جديدة من خريجي كليات الزراعة لئ

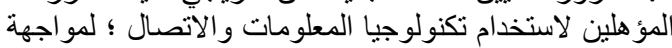

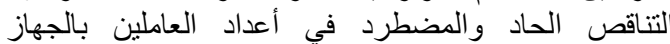
الإرشادي الزراعي. Y. وضع استراتيجية قومية لإعادة تفعيل استخدام تكنولوجيا

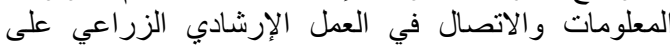

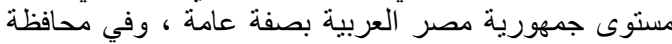
أسيوط بصفة خاصة ، تكون نقطة البدء فيها من خلال استخدام الهاتف المحمول ؛ حيث تبين امتلاك نسبة مرتفعة من فئتي فئي المبحوثين لله ومعرفتهم كيفية استخدامه.

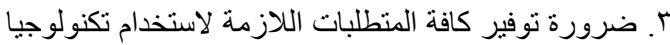

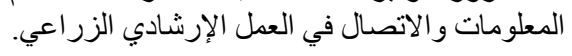
ع. ضرورة زيادة مصادر معلومات فئتي المبحوثين (العاملين

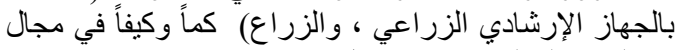
تكنولوجيا المعلومات والريات الزراتصيال.

ه. وضع وتنفيذ برامج تدريبية حديثة في مجال تكنولوجيا أوليا

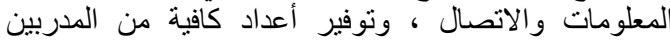
المؤ هلين في ذلك المجال.

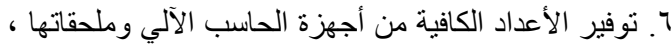
ونقاط الإنترنت السلكي و اللاسلكي ، و الكوادر الفنية المؤهلة الهية

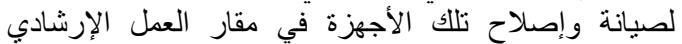
الزراعي. V. ضرورة الاهتمام بإعادة تفعيل دور المراكز الإرشادية 


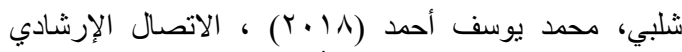

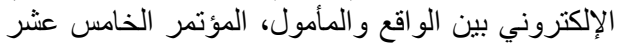

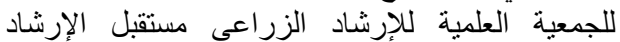

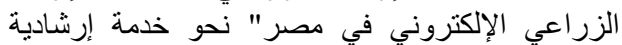

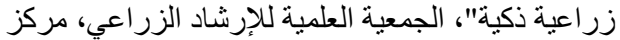

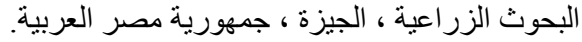

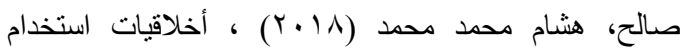

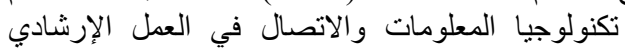

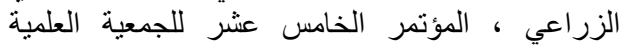

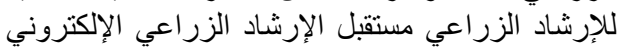

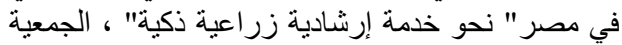

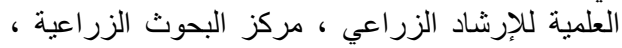
الجيزة ، جمهورية مصر العربية.

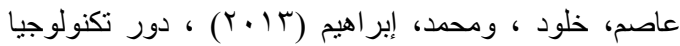

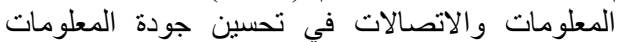

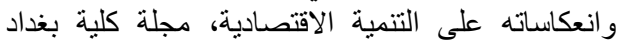
للعلوم الاقتصادية الجامعة، العدد الخاص بمؤتمر الكلية.

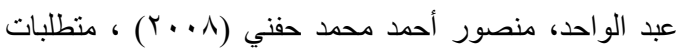

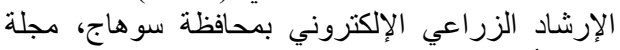

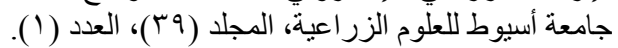

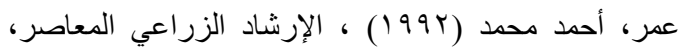

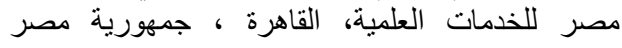

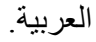

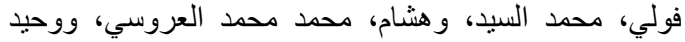

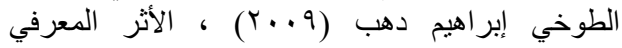

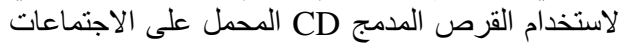

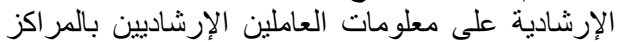

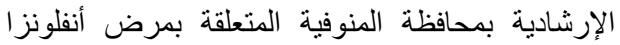

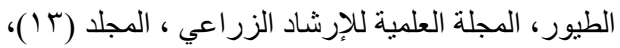

العدد (1). (1).

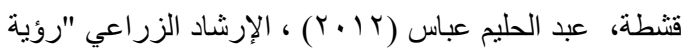

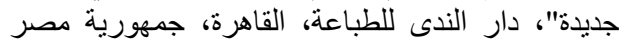

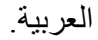

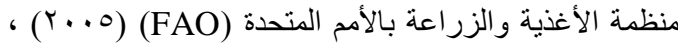
تحديث أنظمة الإرشاد الزراعي الأبي الوطنية، دليل عملي

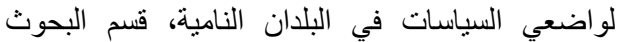
والإرشاد والتدريب، مصلحة التنمية المستدامة، منظمة النامة الأغذية و الزر اعة للأمم المتحدة.
الزراعي، وزارة الزراعة واستصلاح الأراضي،

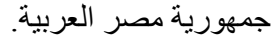

السليلي، محمد أبو الفتوح ، وسعيد، عباس محمد رشاد، وعيد

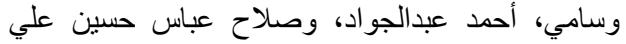

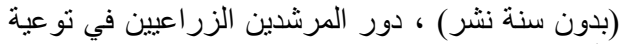
الأسر الريفية بالتشريعات الخاصة بحماية البيئة الريفية من التلوث بمحافظة القليوبية ، جمهورية مصر العربية العربية. الثافعي، عماد مختار، وزينب، حسن مجد، و علي هانثم

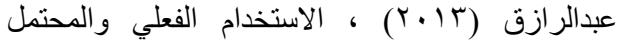

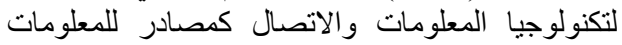

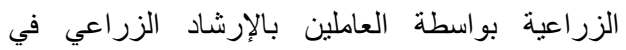

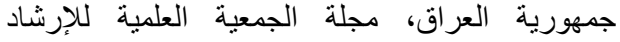
الزراعي، مجلد (V) (Y)، العدد (r).

العادلي، أحمد السيد (19Vr) ) أساسيات علم الإرشاد الزراعي، دار المطبوعات الجديدة، جمهورية مصر الإنيات

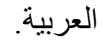

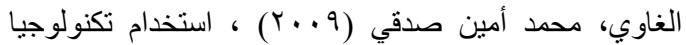

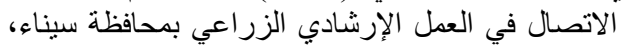

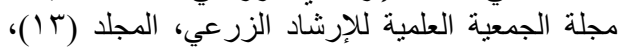
العدد (T). (T) (ل)

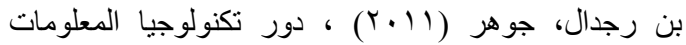

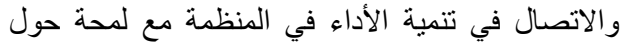

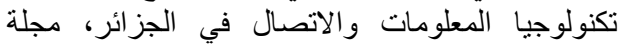
الاقتصاد و التتمية البشرية، المجلد (ع)، العدد (1)

حافظ، مصطفى كمال ، وصفاء، أحمد فهيم البنداري الديب الإنبان

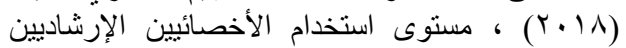
للحاسب الآلي وتطبيقاته في العمل الإرشادي الزين الزراعي

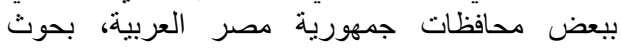
ودراسات الإرشاد الزراعي الإلكتروني الصادرة عنة الفربة

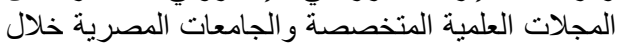

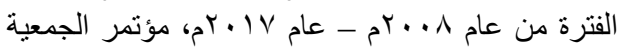

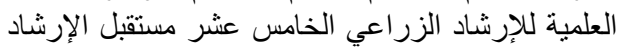

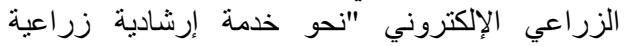
ذكية"، الجمعية العلمية للإرشاد الزراعي، جمهورية العية العية

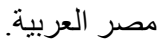

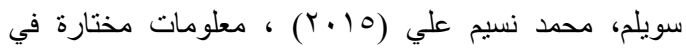

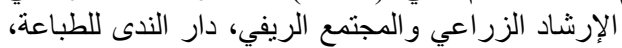
جمهورية مصر العربية. 


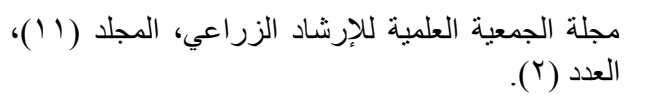

Agha, N., Ghanghas, B. and Chahal, P. K. (2018). "Use of information and communication technologies by extension personnel to disseminate agricultural information", International Journal of Current Microbiology and Applied Sciences, Vol. 7 No. 4, pp. 1369-1376.

Aniebiet Inyan, N. (2015), "Utilization of information and communication technology (ICT) resources and job effectiveness among library staff in the university of Calabar and cross river university of technology, Nigeria", Journal of Education and Practice, Vol. 6 No. 6, pp. 102-105.

Boateng, M. S. (2012), "The role of information and communication technologies in Ghana's rural development", Library Philosophy and Practice, paper 871, pp. 11-16.

Gelb, E., Maru, A., Brodgen, J., Dodsworth, E., Samii, R. and Pesce, V. (2008), Adoption of ICT* Enabled Information Systems for Agricultural Development and Rural Viability, Pre-Conference workshop summary, The AFITA, IAALD and WCCA Conference, Atsugi, Japan.

Gregg, J. A. and Irani, T. A. (2004), "Use of information technology by county extension agents of the Florida Cooperative Extension Service",

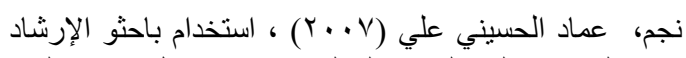
الزراعي لتكنولوجيا المعلومات والاتصال في عملهم،

ثانياً: مراجع باللغة الإنجليزية

Journal of Extension, Vol. 42 No. 3, Retrieved from http://www.joe.org/joe/2004june/rb2 .shtml.

Grimes, S. (1992), "Exploiting information and communication technologies for rural development", Journal of Rural Studies, Vol. 8. No. 3, pp. 269-278.

Hosseini, S. J. F., Niknami, M. and Chizari, M. (2009), "To determine the challenges in the application of ICTs by the agricultural extension service in Iran", Journal of Agricultural Extension and Rural Development, Vol. 1 No. 1, pp. 027030 .

Hussain, S. S. (2016), Use Information and Communication Technology (ICT) for enhancing efficiency in Agriculture, Retrieved from https://www.researchgate.net/public ation/305326591.

Sylvester, G. (2015), Success stories on information and communication technologies for agriculture and rural development, Food and Agriculture Organization of the United Nations Regional Office for Asia and the Pacific, Bangkok, Thailand. 